\title{
News Sharing on Social Media * Mapping the Ideology of News Media Content, Citizens, and Politicians
}

\author{
Gregory Eady $^{\dagger}$ \\ Richard Bonneau ${ }^{\S}$ \\ Joshua A. Tucker• \\ Jonathan Nagler
}

This article examines the news sharing behavior of politicians and ordinary users by mapping the ideological sharing space of political information on social media. As data, we use the near-universal currency of online political information exchange: URLs (i.e. web links). We introduce a methodological approach (and statistical software) that unifies the measurement of political ideology online, using social media sharing data to jointly estimate the ideology of: (1) politicians; (2) social media users, and (3) the news sources that they share online. Second, we validate the measure by comparing it to well-known measures of roll call voting behavior for members of congress. Third, we show empirically that legislators who represent less competitive districts are more likely to share politically polarizing news than legislators with similar voting records in more competitive districts. Finally, we demonstrate that it is nevertheless not politicians, but ordinary users who share the most ideologically extreme content and contribute most to the polarized online news-sharing ecosystem. Our approach opens up many avenues for research into the communication strategies of elites, citizens, and other actors who seek to influence political behavior and sway public opinion by sharing political information online.

Version: November 10, 2020

\footnotetext{
${ }^{\star}$ We are grateful to the members of NYU's Center for Social Media and Politics (CSMaP) for their helpful comments and suggestions. Open-source software for the method introduced in this article, mediascores, is available for download for the statistical software R on GitHub at https://github.com/SMAPPNYU/mediascores/. (for eventual submission to CRAN)

${ }^{\dagger}$ Assistant professor of Political Science, University of Copenhagen, gregory . eady@gmail . com

${ }^{\S}$ Professor, Center for Social Media and Politics, New York University, ri chard . bonneau@nyu . edu

- Professor of Politics, Center for Social Media and Politics, New York University, joshua . tucker@nyu . edu

${ }^{\circ}$ Professor of Politics, Center for Social Media and Politics, New York University, jonathan . nagler@nyu . edu
} 
News_Media_Scaling.tex, November 10, 2020, 1:34pm- NYC

\section{Introduction}

Political information is increasingly consumed online. In the United States, a majority of votingage citizens under the age of fifty now report frequently consuming their political news through online sources (Shearer, 2019). The consequences of this change in the information environment are potentially large, and has resulted in contentious debate. Much of the debate has centered around the political use and ideological orientation of online information and its potential link to polarization. Politicians have expressed concern, for example, about the consumption of news content by the public that does not challenge their ideological viewpoints (echo chambers) (BBC News, 2017); the selective display of ideological content by social media and search algorithms (filter bubbles) (Kang et al., 2018; Wakabayashi and Kang, 2018); and the alleged suppression of ideologically conservative content by social media companies (Herrman and Isaac, 2016).

Before the advent of social media, news consumption was heavily controlled by a small number of traditional news media organizations (Prior, 2007). However, with the growth of social media and the resulting ease of political communication between ordinary citizens, much of our news consumption is now heavily mediated through political information sharing. Online information-sharing has, furthermore, become central to the electoral connection between legislators and their constituents.

Despite its importance, researchers currently lack a unified and straightforward framework for measuring and assessing the ideological leanings of the content shared on social media. This means that we cannot easily describe how politicians and ordinary citizens present themselves ideologically through the news and commentary that they share, nor can we map the ideological structure of the online news environment. In this paper, we help remedy this by providing a methodological foundation for investigating information-sharing behavior on social media by mapping the ideological sharing space of ordinary users (i.e., the mass public) and politicians online; generating ideology measures of media outlets that are shared on social media or 
analogous platforms; and examining, substantively, the political sharing behavior of ordinary users and politicians.

To begin, we introduce a statistical approach that unifies measurement strategies across social media platforms. As data, we use the fundamental building blocks of online information sharing: URLs (i.e. web links). ${ }^{1}$ By leveraging data containing the URLs of news stories and political commentary shared on social media by politicians and users, we generate commonscale estimates of three important quantities of interest: the ideology of (1) politicians, (2) ordinary users, and (3) the news content that they share online. Substantively, our approach enables us to map the structure of ideological sharing on social media; to investigate the ideology of news media organizations as determined by the sharing behavior of users; to examine variation in the polarization of citizens and politicians on social media; and to explore differences between the voting behavior and media sharing behavior of legislators.

Our approach has a number of advantages over other extant techniques to measure ideology. First, unlike past approaches, our measurement strategy is platform-agnostic. Because news media URLs are widely shared across social media platforms, the method we introduce can be applied to data both within and across current social media platforms (e.g. Facebook, Twitter, Reddit) and can, in principle, be applied to any future social media platform on which URLs are shared. Second, unlike past approaches, it does not require partisan or ideological labels of the users who share such information. Third, the method allows us to examine the ideology of politicians on social media based on their online behavior free from constraints imposed on them by a legislative agenda they might not control or from explicit party discipline influencing their roll call voting behavior. Fourth, because social media sharing is a highly dynamic behavior, the data we use allow us to track the ideology of social media users and political actors across time. Fifth, the method we introduce permits researchers to capture, as a natural outcome of our model, variation in the extent to which users and political actors share ideologically diverse

\footnotetext{
'The acronym 'URL' stands for Uniform Resource Locator, although it is better known by its acronym. URLs are also frequently referred to more colloquially as 'web addresses' or 'links' (e.g. www.nytimes.com/2018/02/13/upshot/fake-news/...). We use these terms interchangeably throughout.
} 
(or ideologically narrow) information, with implications for the study of sharing behaviors that promote or discourage the development of polarization or echo chambers on social media. Finally, our approach permits estimation of the ideology of little-known political candidates who have no previous voting records (the typical data used to estimate ideology of legislators).

This paper proceeds as follow. First, we briefly summarize the literature on the measurement of ideology using social media data, and the literature on the measurement of ideology of offline and online news media. Second, we describe the social media link data that we use to estimate the ideology of users, politicians, and the news media content that they share. Next, we introduce and estimate our statistical model of news media sharing behavior. We validate our estimates against existing measures of political ideology, and provide descriptive representations of the ideology of users, politicians, and news media online. In doing so we demonstrate that alternative measures of ideology lead to substantially different mappings of the ideological distribution of the mass public versus legislators. We then apply our approach to examine how the competitiveness of districts influences the ideological sharing behavior of legislators. We close with a discussion of the opportunities opened up by our approach by suggesting avenues for future work.

Our empirical research proves four important facts about the online political informationsharing ecosystem. First, it is citizens-not politicians—who share the majority of ideologically polarized political news and commentary online. Second, the news content shared by legislators is an exceptionally strong signal of political ideology and partisanship, nearly perfectly separating politicians by party. Third, there are strong within-party differences in ideologically polarized information-sharing: politicians in both the Democratic and Republican parties who are on the ideological extremes share more information than their more moderate peers, and they share more extreme (polarizing) political news and commentary. Finally, we show that this is linked to variation in electoral incentives for ideological moderates and extremists. Legislators in competitive districts are both more likely to share more moderate news and commentary, and least likely to share political news overall. 


\section{Political Ideology of Social Media Users and News Media}

In the study of politics, few research programs have been more productive, wide-ranging, and consequential for testing theories of political behavior than those seeking to measure the political ideology of politicians, institutions, and citizens. Beginning with the introduction of the wellknown NOMINATE procedure to measure legislator ideology with roll-call votes (Poole and Rosenthal, 1985; Poole, 2005), the literature has since greatly advanced these measurement techniques, expanding them into new areas of theoretical and empirical interest. Methods have been developed to measure the ideology of legislators (Poole and Rosenthal, 1985; Heckman and Snyder Jr., 1997; Clinton, Jackman and Rivers, 2004), political donors (Bonica, 2013, 2014, 2018), interest groups (Groseclose, Levitt and Snyder Jr., 1999; McKay, 2008; Crosson, Furnas and Lorenz, Forthcoming), Supreme and lower-court justices (Martin and Quinn, 2002; Jessee and Malhotra, 2013; Bonica and Woodruff, 2015; Bonica and Sen, 2017), newspapers (Groseclose and Milyo, 2005; Ho and Quinn, 2008; Gentzkow and Shapiro, 2010, 2011), municipalities (Tausanovitch and Warshaw, 2014), and government agencies (Richardson, Clinton and Lewis, 2018). Substantial effort has also been put into measuring the ideology of ordinary citizens and political actors on a common ideological scale (Aldrich and McKelvey, 1977; Jessee, 2009; Bafumi and Herron, 2010; Bonica, 2013, 2014; Jessee and Malhotra, 2013; Hare et al., 2015; Jessee, 2016).

The measurement of ideology on social media, however, is relatively new, and has focused heavily on that of politicians and users rather than the content they share. Below, we briefly review current approaches to the study of the ideology of social media users and news media ideology. We then introduce our statistical approach to generalize and unify these approaches to investigate the ideological structure of social media sharing behavior.

\subsection{User ideology on social media}

Two new techniques to measure the ideology of social media users and political actors have recently been introduced in political science (Barberá, 2015a; Bond and Messing, 2015). These 
measurement approaches were developed to measure ideology on two of the most politically consequential social media platforms: Facebook and Twitter. The data used in these works are roughly analogous: Bond and Messing (2015) use data that capture which political actors users 'endorse' on Facebook; Barberá (2015a) uses data that capture the political actors that users 'follow' on Twitter. The models are based on the homophily assumption: social media users are assumed to endorse or follow political actors who they perceive to be close to them ideologically, but not those who are ideologically distant. A liberal user, for instance, is assumed to endorse or follow more liberal political actors; a conservative, more conservative actors. This homophily assumption and its empirical foundations are well-known (McPherson, Smith-Lovin and Cook, 2001). As Bond and Messing (2015) and Barberá (2015a) show, spatial models of ideology that rely on this assumption for social media data work well in practice. ${ }^{2}$ These approaches have since spurred important applied research to answer questions concerning a wide range of political behavior on social media (e.g. Theocharis et al., 2016; Bail et al., 2018; Kteily et al., 2019; Barberá et al., 2019).

\subsection{News media ideology}

Unlike approaches to the measurement of ideology on social media, which are relatively recent, strategies for estimating the ideology of news media have a longer pedigree and span the offline and online media landscape. Ho and Quinn (2008), for example, develop an item-response model to measure the ideology of news media and Supreme Court justices using as data news editorial agreement with Supreme Court justices on individual cases. Others have successfully used existing measures of ideology in one domain, such as voting records, to estimate the ideology with supervising learning methods in another. Martin and Yurukoglu (2017), for instance, estimate the ideology of news organizations by measuring similarities in the language used by those

\footnotetext{
${ }^{2}$ Unlike in political science, much of the literature in machine learning treats the measurement of political ideology as a classification task (e.g. 'liberal' or 'conservative'), rather than one to capture ideology on a continuous scale (e.g. Boutet, Kim and Yoneki, 2012; Conover et al., 2011; Cohen and Ruths, 2013; Preoţiuc-Pietro et al., 2017). For many questions in political sciences, however, discrete labels are insufficient, preventing, for instance, differentiation among politicians of the same party, and users and media content that ranges across the ideological spectrum.
} 
organizations and that used by Members of Congress who have a 'known' ideology (e.g. a NOMINATE score) (see also, Groseclose and Milyo, 2005; Gentzkow and Shapiro, 2010; Martin and McCrain, 2019; Wihbey, Joseph and Lazer, 2019). Another approach is to crowd-source perceptions of the ideology of media organizations (Budak, Goel and Rao, 2016). Finally, others estimate the ideology of news media by consumer behavior. Similar to supervised approaches in which the ideology of some actors are known, estimates of the ideology of news organizations are calculated based on the proportion of consumers of content by each organization who are self-reported liberals or conservatives (e.g. Gentzkow and Shapiro, 2011; Pew Research Center, 2014; Bakshy, Messing and Adamic, 2015; Grinberg et al., 2019), or by averaging the NOMINATE scores of the politicians who share news from those organizations (Messing, van Kessel and Hughes, 2017).

\section{Unifying the Study of Social Media and News Media Ideology}

In this section, we seek to unify approaches to measuring the ideology of social media users, politicians, and news media. To do so, we argue for the use as data of the near-universal currency of social media information exchange: the URLs shared by ordinary users and politicians.

Our focus on URLs is guided by the theoretical, empirical, and practical benefits of link data. First, because URLs are the fundamental building block of social media sharing, they are ubiquitous across social media platforms. This permits us to develop a platform-independent measure of political ideology that allows for a common-scale measure of ideology both within platforms and across them, opening up investigation into variation in sharing behavior across platforms. Given that link sharing is the primary method of news information sharing online, such data should enable researchers to obviate the development of unique approaches for future platforms that are dependent on each platform's idiosyncratic features.

Second, the sharing of political information on social media, especially URLs, is now a central method for politicians and other political actors to communicate with their constituents and the general public. The sharing behavior of political actors is itself, in other words, an area of 
substantive importance for understanding political communication and political behavior more generally. Furthermore, the sharing of information online through political news is a central mode for political discourse among ordinary citizens and is also increasingly a means for foreign actors to interfere in Western and emerging democracies. Examination of news sharing online is of critical importance for understanding day-to-day political discourse and, in international relations, the strategies of foreign actors.

Third, unlike past approaches to estimating political actors' ideology using social media data, URL sharing is a behavioral measure of ideology at the level of each politician. Previous approaches, by contrast, have examined ideology indirectly, relying on social media users' perceptions of politicians, such as through users' following and endorsement choices. Such measures are important in their own right: user perceptions are critical to understanding behavior online. But by using data from politicians' sharing behaviors themselves, we provide an important avenue for investigating the communication strategies of campaigns and constituentpolitician interactions. This allows us to examine, for example, how the information presented by legislators online differs from that signaled by their voting behavior. ${ }^{3}$ Furthermore, because URL sharing data are available for users and politicians, both sets of actors can be treated equivalently, placed on a common behavior-based ideological scale. ${ }^{4}$

Fourth, because sharing lies at the foundation of social media usage, the sharing of URLs by users and politicians is relatively frequent. This attribute of URL sharing data facilitates investigation into changes in sharing behavior and ideology across time, an important but challenging area of research. For example, this allows inquiry into whether social media leads to political polarization among individuals over time or whether the ideology of sharing behavior changes closer to elections or in response to high-profile events. The relatively high frequency of URL sharing, furthermore, increases the precision of the estimates of social media users' ideology

\footnotetext{
${ }^{3}$ Tausanovitch and Warshaw (2017) argue that researchers should take seriously the reasons why measures of ideology differ across domains. In an application below, we investigate why the social media sharing ideology of Members of Congress differs from that of their voting ideology.

${ }^{4} \mathrm{~A}$ related practical benefit is that we can estimate the ideology of politicians using only their social media feeds, avoiding the collection of data from tens of millions of the users who interact with them.
} 
relative to other possible indicators.

Finally, using the sharing behavior of news media URLs by social media users and politicians allows us to map the structure of news media ideology based on how news media are used in practice. This behavioral approach is similar to that of Bakshy, Messing and Adamic (2015), who estimate the ideology of news media by calculating the difference in the proportion of self-reported liberals and conservatives who share links to such media, and Messing, van Kessel and Hughes (2017), who calculate media ideology by averaging the NOMINATE scores of Members of Congress who share news media URLs. However, our model, which we present below, does not rely on existing measures of ideology in another domain such as voting behavior in congress or self-reporting. Instead, as we detail in the following section, our approach allows us to map the ideological space specific to social media sharing by placing users, politicians, and news media on a common scale based on sharing behavior alone.

\section{A Statistical Model of Social Media News-Sharing Behavior}

In this section, we propose a model of social media sharing ideology by using news media URLs as data. To make the goal of our measurement strategy more concrete, we begin by detailing our data, after which we introduce our statistical model.

\subsection{Data}

As we point out above, our approach is platform-agnostic and can therefore be applied to any social media platform on which users and political actors alike share links to political news media. For the analyses presented here, we use data from Twitter. Our reasons are fourfold. First, the vast majority of Members of Congress in the US (99\%) have Twitter accounts, many of which contain posts that link to media articles and political commentary. These data allow us to validate our statistical model against well-known measures of the ideology of Members of Congress and to simultaneously test whether politicians with more extreme voting records share more ideologically extreme news content. Second, and more pragmatically, Twitter's application 
programming interface (API) provides straightforward access to these data and those from all ordinary Twitter users who have not marked their Twitter profiles as private. ${ }^{5,6}$ Lastly, the most widely applied method in political science research for the measurement of ideology on social media is specific to the Twitter social media platform (Barberá, 2015a). Using Twitter data thus allows us to compare our results to those from the most widely use method for scaling social media data in political science research.

To collect our data, we begin by compiling a list of the Twitter accounts of all US Members of Congress; state governors; members of the executive and cabinet; and accounts associated with prominent unelected members of the Democratic and Republican parties. Our collection procedure for defining and collecting these accounts of political elites is detailed in the Supplementary Material. The list contains 628 political actors in total. We then define the set of national news media organizations online. To do so, we define our population of political media websites as all sites that provide news or commentary about national politics, including sites from television media (e.g. cnn.com; foxnews.com), traditional print journalism (e.g. nytimes.com; wsj.com), and commentary (e.g. nationalreview.com; newrepublic.com). News and commentary sites include, furthermore, those that are generally considered highly partisan (e.g. dailycaller.com; thinkprogress.com), and thus sites expected to be on the extremes of the ideological spectrum-a useful check on the face validity of our statistical measurement approach introduced below. In total, the list of national media organizations contains 214 domains. The complete list of domains is available in the Supplementary Material.

To compare the news sharing behavior of politicians to that of ordinary citizens, we require a sample of ordinary social media users. To collect this, we follow the procedure proposed by Barberá $(2015 a)$, who defines the population of minimally politically engaged Twitter users as all

\footnotetext{
${ }^{5}$ At the time of writing, the Twitter API permits access to the 3,200 most recent tweets from each user timeline. ${ }^{6}$ Also, the shortened URLs included in Tweets (e.g. nyti.ms/2BUTshD) that are sent by users through Twitter's user interface are automatically expanded (e.g. www.nytimes.com/2018/02/13/upshot/fake-news/...), reducing the number of URLs that require manual expansion. We unshorten all remaining shortened links. The unshortening of URLs is a time-consuming process even with multi-threaded code, a drawback to using link data. Social media providers, however, arebeginning to provide these links to researchers in an unshortened format (e.g. Facebook \& Social Science One, 2018).
} 
those who follow a researcher-defined threshold of Members of Congress. To capture as wide a population of minimally engaged users as possible, we define our population of interest as all users geo-located to the US who follow one or more politicians ( $\sim 154$ million users $){ }^{7}$ Because collecting and processing the URLs for all possible users is computationally demanding and time-consuming, we sample 50,000 users from this population.

For each account, we collect all tweets made available by Twitter from each political actor and ordinary user. ${ }^{8}$ We then extract all URLs from each tweet and expand any shortened links. ${ }^{9}$ For analysis, we use any URL included in tweets that were authored by a given user, and those in tweets that were retweeted by the user. We exclude URLs that are included in the quoted portion of 'quote tweets'. Quote tweets are those in which a user quotes another tweet to comment on it and are often used to criticize or satirize the content.

To show graphically the distribution of these data aggregated across all users, we present in Figure 1 the fifty most tweeted of these national political commentary and news domains as a proportion of all such domains. As the figure shows, the most frequently shared links are to well-known traditionally print news (e.g. New York Times, Washington Post, Wall Street Journal), and the major television media organizations (e.g. CNN, FOX News, NBC, ABC). By contrast, only a few periodicals dedicated to political commentary (e.g. The New Yorker, Foreign Policy, The Weekly Standard) find themselves among the most frequently shared domains. Data for the proportions of links shared from all news domains $(n=214)$ are provided in the Supplementary Material.

To aggregate these data, for all users $i=1, \ldots, N$ and media domains $m=1, \ldots, M$, we generate an $N \times M$ user-domain count matrix. In other words, each cell in the matrix simply represents the number of times that a given user $i$ has tweeted a story from media organization $m$. To see this by example, Table 1 presents a sub-matrix of our data for six well-known Republicans and Democrats

\footnotetext{
${ }^{7}$ We geolocate users based on a combination of self-reported location of Twitter users provided in meta-data, and similar data provided in the reciprocal friend-follower networks of users.

${ }^{8}$ Twitter data from politicians and ordinary users were collected between August and December, 2018, and include up to the most recent 3,200 tweets from each politician and user.

${ }^{9}$ The vast majority of shortened links can be expanded to retrieve the page that they point to.
} 
Figure 1: Fifty most tweeted national political commentary and news media domains as a proportion of all commentary/news domains shared by Members of Congress and users

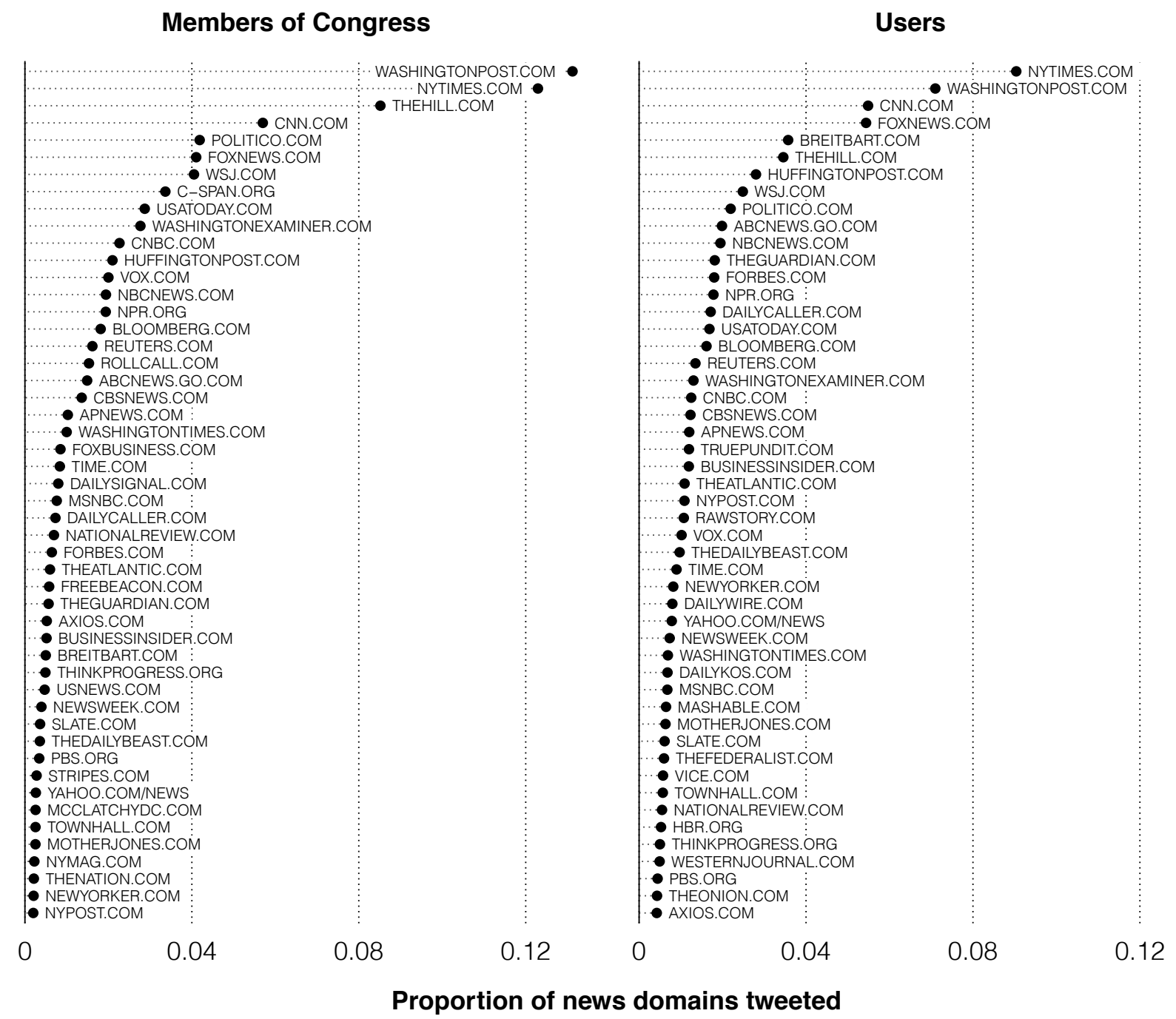

This graph shows the domains of the fifty most frequently tweeted domains as a proportion of all domains identified as national political news media. Details for all domains are provided in the Supplementary Material.

(rows) and five media domains (columns). As these data appear to suggest, Republican politicians appear more likely to tweet links to media stories right of center (foxnews.com; breitbart.com) than they are those left of center (thenation.com; huffingtonpost.com); Democrats, more likely to tweet links to media stories to the left than they are those to the right.

Before turning to our measurement model, we first investigate the number of news media URLs shared by Democratic and Republican politicians as a proportion of their overall twitter activity, comparing them to ordinary users. To do so, Figure 2 shows the number of stories 
Table 1: Example of social media user-media domain count matrix

\begin{tabular}{|c|c|c|c|c|c|c|}
\hline & thenation.com & huffingtonpost.com & washingtonpost.com & wsj.com & foxnews.com & breitbart.com \\
\hline Ted Cruz (R) & 0 & 0 & 23 & 6 & 44 & 6 \\
\hline Paul Ryan (R) & 0 & 0 & 5 & 8 & 14 & 0 \\
\hline Susan Collins (R) & 0 & 1 & 3 & 2 & 0 & 0 \\
\hline Claire McCaskill (D) & 0 & 4 & 25 & 10 & 2 & 0 \\
\hline Nancy Pelosi (D) & 0 & 2 & 17 & 0 & 0 & 0 \\
\hline Bernie Sanders (I) & 12 & 14 & 62 & 4 & 0 & 0 \\
\hline$\vdots$ & $\vdots$ & $\vdots$ & $\vdots$ & $\vdots$ & $\vdots$ & $\vdots$ \\
\hline
\end{tabular}

This table presents a sub-matrix of the counts of news organization URLs tweeted by Members of Congress. Non-zero counts in bold.

Figure 2: Mean number of news media domains shared by users on Twitter (per tweet)

Members of Congress

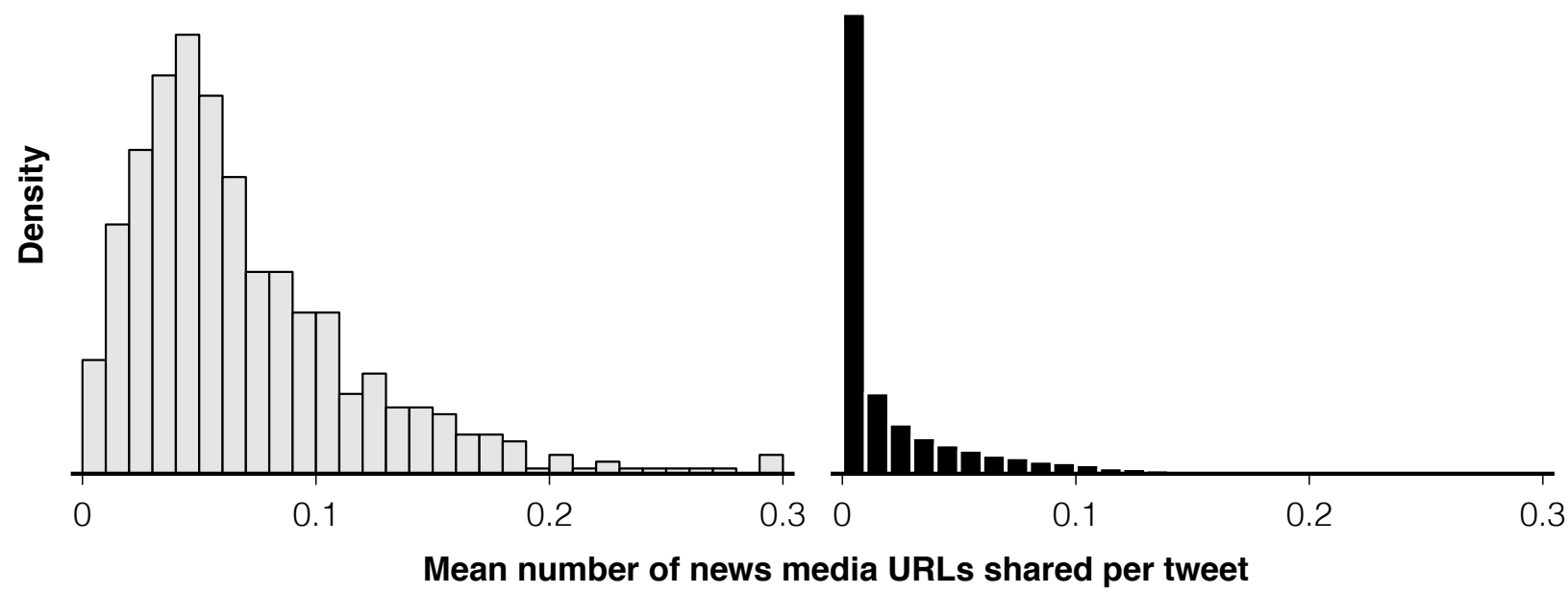

This graph shows the density of the mean number of news media domains shared per tweet by Members of Congress and ordinary users.

from political media domains that are shared in our Twitter data by Democratic and Republican Members of Congress as a proportion of their average number of tweets, and the same for ordinary users.

As we can see the average member of Congress shares approximately 0.084 news-media URLs per tweet. For ordinary users, the frequency of sharing news-media-URLs is much lower at 0.037 news media URLs per tweet. The mean number of URLs included in each tweet might, however, obscure the frequency of including at least one URL, since any tweet can contain multiple URLs. Thus an alternative way to compare frequency of URL use is to note that among members of Congress, $67 \%$ send or retweet a tweet with a national news media URL in at least 5 out of every 
100 tweets sent. By contrast, only $23 \%$ of ordinary users share at least 5 national news media URLs per 100 tweets. $^{10}$

\subsection{A Statistical Model of News-Sharing on Social Media}

To estimate the ideology of (1) the media organizations from which social media users and political actors share political news, and (2) the ideology of those users and actors themselves, we develop an item-response model for the news media URLs that are shared on social media. Consistent with the data described above, let $y_{i m g}$ denote the count of the media domain $m=1, \ldots, M$ shared by a user or political actor $i=1, \ldots, N$ who is affiliated with the group $g \in\{\mathrm{D}$, R, U\} (Democrat, Republican, Unaffiliated). ${ }^{11}$ Concretely, $y_{i m g}$, in other words, denotes the value of a single cell in Table 1, where the columns represent the media organizations $m$, and the rows represent the users/actors $i$ affiliated with group $g$.

To model these data in a way consistent with our spatial assumption of news sharing, we introduce two latent variables as our primary quantities of interest. The first, $\theta_{i g}$, denotes the ideology of user $i$ (affiliated with group $g$ ); the second, $\zeta_{m}$, the ideology of a given media organization $m$. As shorthand, we refer to both of these parameters as media scores, making clear by context whether we are referring to individual users or media organization domains. We model the data, $y_{i m g}$, as arising from a negative binomial (count) distribution as follows:

$$
\begin{gathered}
y_{i m g} \sim \operatorname{NegBin}\left(\pi_{i m g}, \omega_{i} \omega_{m}\right) \\
\pi_{i m g}=\exp \left(\alpha_{i}+\gamma_{m}-\left\|\theta_{i}-\zeta_{m}\right\|^{2}+\mathbf{x}_{i}^{\prime} \boldsymbol{\beta}\right),
\end{gathered}
$$

where $\alpha_{i}$ denotes a user-specific intercept, $\gamma_{m}$ denotes a domain-specific intercept, and $\mathbf{x}_{i}$ and $\boldsymbol{\beta}$ denote vectors of user-specific covariates and parameters respectively. Lastly, $\omega_{i}$ and

\footnotetext{
${ }^{10}$ In addition, Members of Congress have at least 1 news URL in $8.4 \%$ of their tweets, whereas our set of ordinary users have at least 1 news URL in only $3.7 \%$ of their tweets.

${ }^{11}$ Note that 'Unaffiliated' can also simply be interpreted as 'unknown': for members who are not known to be Democrats or Republicans, we are simply specifying distinct priors for each of the three groups, and taking advantage here of the fact that the group membership of Members of Congress is a known quantity.
} 
$\omega_{m}$ denote user- and domain-specific dispersion parameters. Substantively, $\alpha_{i}$ represents the relative extent to which a given user shares news in general, and $\gamma_{m}$ the relative extent to which a given media domain is shared (i.e., the popularity of the media domain). The term containing our quantities of interest, $-\left\|\theta_{i}-\zeta_{m}\right\|^{2}$, captures the notion that the larger the distance between the ideology of a given user $\left(\theta_{i}\right)$ and a given media organization $\left(\zeta_{m}\right)$, the less likely that user is to share links to that organization's news content. Lastly, although dispersion parameters are rarely given substantive interpretation, $\omega_{i}$ and $\omega_{m}$ represent important quantities: the extent to which a given user's sharing behavior is predictable based on their ideology (and other measured covariates), and the extent to which a given domain being shared is predictable given user's ideology. ${ }^{12}$ These parameter, in other words, captures the extent to which a given user shares media consistent with his or her ideology, or shares information from sources more broadly across the ideological spectrum.

For estimation in a Bayesian framework, we place priors on each group of parameters, and set constraints as necessary to identify the model. ${ }^{13}$ In particular, the user- and domain-specific intercepts are each given common distributions, $\alpha_{i} \sim \operatorname{Normal}\left(\mu_{\alpha}, \sigma_{\alpha}\right)$ and $\gamma_{i} \sim \operatorname{Normal}\left(0, \sigma_{\gamma}\right)$ respectively. We use group-level information about users, $g \in\{D, R, U\}$ (Democrat, Republican, Unaffiliated), by placing separate common prior distributions on the parameters denoting the ideology, $\theta_{i g}$, of politicians who are members of the Democratic and Republican parties, $\theta_{i D} \sim \operatorname{Normal}\left(\mu_{\theta}^{(D)}, \sigma_{\theta}^{(D)}\right)$ and $\theta_{i R} \sim \operatorname{Normal}\left(\mu_{\theta}^{(R)}, \sigma_{\theta}^{(R)}\right)$ respectively. ${ }^{14}$ For identification, the prior distribution for the ideology of ordinary users is set, as is common in typical item-response models, as $\theta_{i U} \sim \operatorname{Normal}(0,1) .{ }^{15}$ The parameters denoting the ideology of media organizations, are given weakly informative prior distribution, $\zeta_{m} \sim \operatorname{Normal}(0,5)$. Finally, the dispersion

\footnotetext{
${ }^{12}$ Dispersion parameters and (un)predictability in statistical and machine learning models are increasingly being given important substantive interpretations for theory testing. One important early case is that by Lauderdale (2010). Recent work in this vein includes research by Gentzkow, Shapiro and Taddy (2019), Peterson and Spirling (2018), Bertrand and Kamenica (2018), and Eady and Loewen (Forthcoming).

${ }^{13}$ All models in this article are fit using the Bayesian inference engine Stan (Carpenter et al., 2017), which provides flexibility in fitting these models to link data from other social media platforms and the inclusion of user-level covariates.

${ }^{14}$ Uniform prior distributions are placed on the hyperparameters $\mu_{\theta}^{(\cdot)}$ and $\sigma_{\theta}^{(\cdot)}$.

${ }^{15}$ Setting the prior $\theta_{i U} \sim \operatorname{Normal}(0,1)$ resolves the problem of additive aliasing caused by the fact that the likelihood is invariant to adding a constant to the parameters $\theta_{i g}$ and $\zeta_{m}$.
} 
parameters, $\omega_{i}$, are given a common distribution $\omega_{i} \sim \operatorname{InvGamma}\left(\omega_{a}, \omega_{b}\right) .{ }^{16}$

To identify the model, we need to address the problem of reflection invariance (Bafumi et al., 2005), which refers to the fact that the likelihood is invariant to multiplication of the parameters $\theta_{i g}$ and $\zeta_{m}$ by -1 . We need, in other words, to fix the direction of the scale such that higher values of $\theta_{i g}$ and $\zeta_{m}$ indicate either liberal or conservative. There are a number of ways to achieve identification (see, for example, Bafumi et al. 2005). Here, we follow Jackman's (2001) practical solution of allowing the sampler to freely explore the posterior and settle in on one of the two scale directions. We then flip the scale after estimation (if required) such that low values of $\theta_{i g}$ indicate liberal, and high values, conservative. ${ }^{17}$

\section{Do Ideologically Extreme Legislators Share more Polarizing News?}

To demonstrate the utility of our measurement approach, we investigate an important substantive question concerning the behavior of politicians: to what extent do Members of Congress signal their ideology through the sharing of political news on social media? Fortunately, our measurement strategy allows us investigate this because one of the key benefits of using data from social media news sharing is that it represents a behavioral measure of ideology among both ordinary citizens and politicians. Thus, whereas past research has relied on the following and endorsement of politicians by ordinary social media users, i.e. a perceptual measure of ideology, the data concerning the content shared by politicians themselves permits measurement based on the behavior of politicians themselves.

To examine the extent to which Members of Congress signal their ideology with political news on social media, we begin by estimating the model using sharing data from the 628 political actors in our dataset: Members of Congress, state governors, members of the executive, and former and current politicians and actors linked to each party (e.g. party chairpersons, former presidents). Using only the subset of politicians from the much larger dataset is beneficial for

\footnotetext{
${ }^{16}$ The hyperparameters $\omega_{a}$ and $\omega_{b}$ are given improper uniform priors Uniform $(0, \infty)$.

${ }^{17}$ We run 4 chains per model, assessing convergence with $\hat{R}$ statistics (Gelman et al., 2014; Carpenter et al., 2017).
} 
Figure 3: Histogram of Ideology of Congress from Social Media Sharing

Democrat $\mathbf{\square}$ Republican

Senate

3

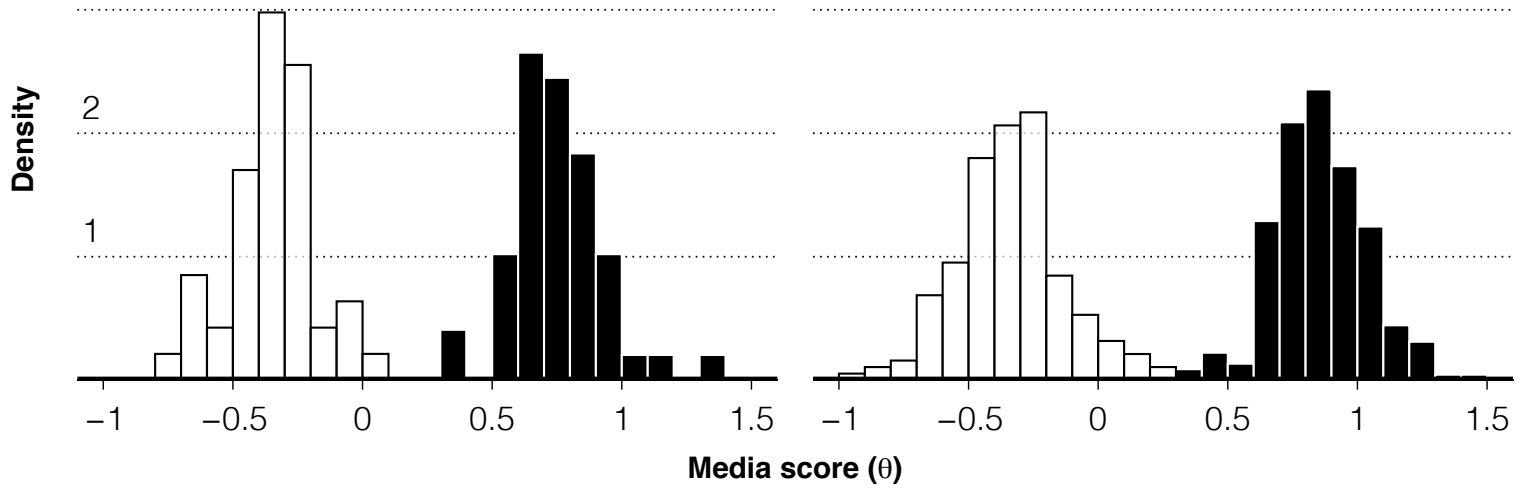

This figure presents histograms of the ideology of Members of Congress as estimated from their social media news sharing behavior.

two reasons. First, as shown by Jessee (2016), the ideological structure that underlies political elite behavior can differ from that of ordinary citizens. By using data solely from politicians, we examine political ideology as it structures social media sharing by political actors themselves. Second, whereas current methods to measure politicians' ideology on social media typically rely on the behavior of hundreds of thousands or millions of ordinary users on Twitter (e.g. Barberá, 2015a) or Facebook (e.g. Bond and Messing, 2015), using data from only the political actors of interest demonstrates the extent to which social media behavioral data from a comparatively small number of actors - politicians themselves - can successfully ideologically differentiate actors both between and within political parties. We show, in other words, that measures of ideology on social media need not require massive amounts of data, which may be unavailable for analysis, time-consuming to collect, and/or computationally demanding to analyze at the scale necessary for estimates of a desired precision. As a robustness check, we nevertheless provide analogous results from the model fit to all data (i.e. including ordinary users). The results are substantively equivalent to those presented below.

We compare estimates of ideology from our item-response model (fit to sharing data from 
politicians' Twitter feeds) first to their partisanship, and then to their ideology as measured by their roll call voting behavior (i.e., DW-Nominate score). To demonstrate the results, Figure 3 presents histograms of the estimated ideology of members of the Senate and House, broken down by the partisanship of Members of Congress. As the figure shows, there is clean separation between members of each party. In fact, no Republican (Democratic) Members of Congress are estimated to the left (right) of their colleagues in the party. Because our model as specified in Equation 1 and 2 uses separate hierarchical priors for the ideology estimates of Republican and Democratic politicians, and thus includes information about party affiliation into the model itself, we also fit an analogous model that removes such information. To do so, we treat the ideology of all politicians as arising from a single common distribution. ${ }^{18}$ Dropping this information is less efficient, but it nevertheless allows us to examine the extent to which media sharing behavior alone - absent any party information — differentiates political actors in ideological space. The results from this model are substantively equivalent. Although there is some overlap between the ideological distributions of Democrats and Republicans, the level of overlap is slight: among members of the House, $7 \%$ of the ideology distributions of Democrats and Republicans overlap; among Senators, $4 \%$. The social media sharing of news by political actors, in other words, nearly perfectly signals the party to which they belong. This is important for two reasons. First, it provides face validity to the measurement approach introduced herein, of which we go into further depth below. Second, and more importantly, it highlights the level of polarization in news media use between members of the parties, such that ideology at the level of the media organization is sufficient to differentiate party members, even in the absence of information about the content of the stories shared themselves. ${ }^{19}$

If the news media domains shared by politicians on social media successfully differentiate between politicians of different parties, how well do they differentiate politicians of different ideologies within parties? To answer this question, in Figure 4 we compare media scores

\footnotetext{
${ }^{18}$ In other words, the ideology of Democratic and Republican politicians are specified to arise from the same common distribution: $\theta_{i D} \sim \operatorname{Normal}\left(\mu_{\theta}, \sigma_{\theta}\right)$ and $\theta_{i R} \sim \operatorname{Normal}\left(\mu_{\theta}, \sigma_{\theta}\right)$.

${ }^{19}$ As we note further below, incorporation of news content itself is an important avenue for future research.
} 
Figure 4: Ideology of Congress from Social Media Sharing Compared to DW-NOMINATE

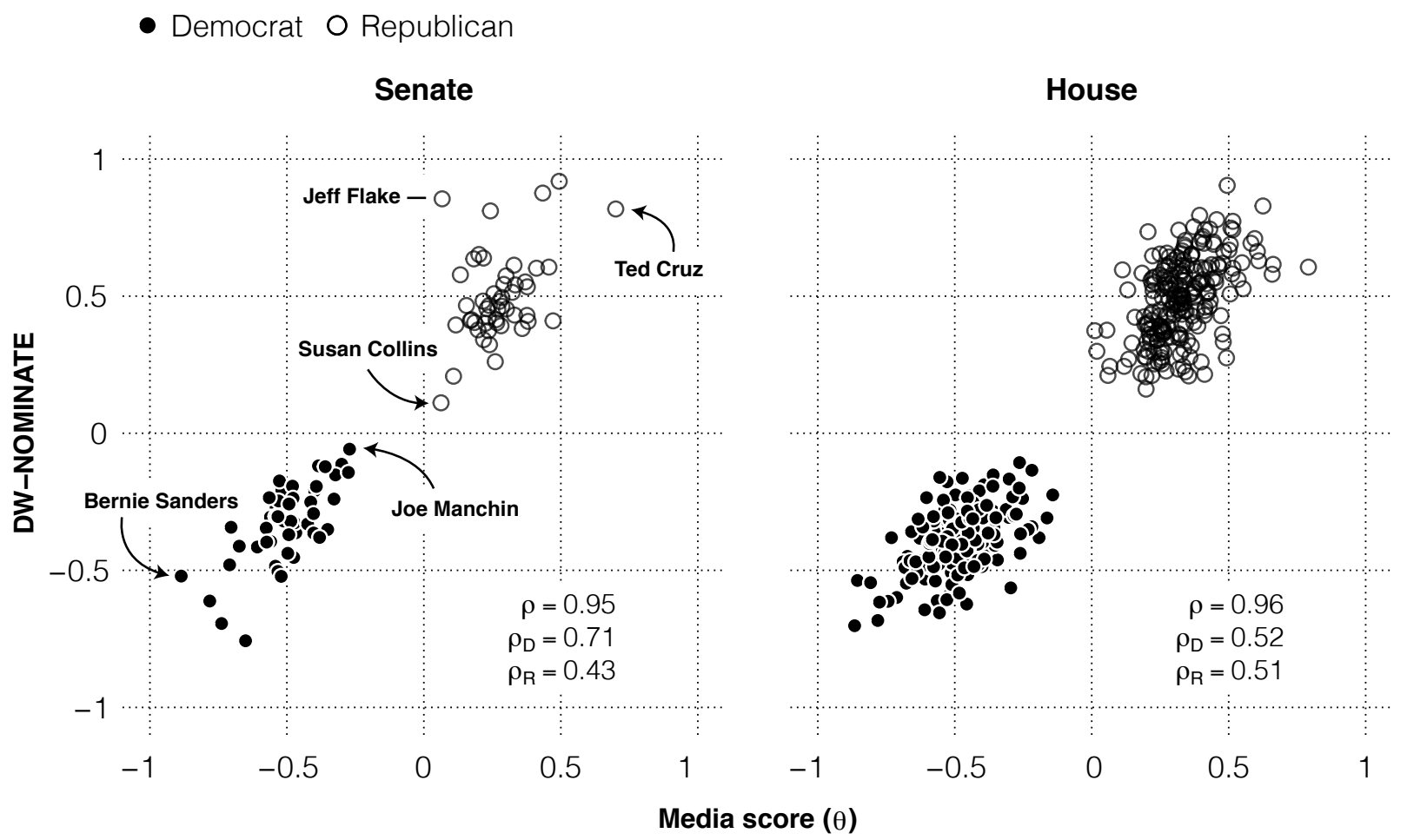

This figure presents the estimated ideology of Members of Congress from legislators' voting records (DW-NOMINATE) to that estimated from their sharing behavior (media score, $\theta$ ).

for individual Members of Congress to estimates of their ideology from the well-known DWNOMINATE scoring procedure (Poole and Rosenthal, 1985; Boche et al., 2018). Consistent with the results presented earlier, the figure shows that the ideology of members of each political party are clearly separated, as they are in roll-call ideology estimates. ${ }^{20}$ But more importantly, the within-party correlations between DW-NOMINATE scores and ideology as estimated from news media sharing behavior are also high, both in the senate $\left(\rho_{D}=0.68, \rho_{R}=0.62\right)$ and in the house $\left(\rho_{\mathrm{D}}=0.58, \rho_{\mathrm{R}}=0.55\right) .^{21}$ Thus the face validity of the estimates is clear, and we see that legislators

\footnotetext{
${ }^{20}$ And the correlation between media score estimates and DW-NOMINATE scores is extremely high $(\rho=0.96)$. However, it is well-known that in multi-modal distributions of ideology, the correlation of measures of ideology can often be high, even if within-party correlations are low. For example, applications of the WORDFISH procedure (Slapin and Proksch, 2008; Lauderdale and Herzog, 2016) to Twitter data can successfully classify legislators by party, but struggle to differentiate the ideology of members within parties (with within-party correlations near zero) (Temporão et al., 2018).

${ }^{21}$ These correlations between Media-Scores and dw-nominate are similar to, but somewhat higher than, correlations between other social-media derived measures and dw-nomiate. For example, within-party correlations with DWNOMINATE scores (from the $111^{\text {th }}$ Congress) using Facebook endorsement data are $\rho_{\mathrm{D}}=0.47, \rho_{\mathrm{R}}=0.42$ (Bond and Messing, 2015). For network based estimates of legislators' ideology from Twitter follower data (Barberá, 2015a)
} 
who vote in a more conservative (liberal) direction also share more conservative (liberal) media sites.

\section{The Ideology of Online News Media Content}

One key benefit of our approach is that we can provide estimates of the ideology of online news media. Thus, whereas a key benefit of our approach as demonstrated in the section above is that the ideology of legislators themselves are estimated as a function of their behavior, so too the ideology of news media organizations are estimated as a function of the sharing behavior of politicians and ordinary users. These estimates provide both a useful description of the ideology of a wide array of news sources, many of which would be difficult to ideologically classify otherwise, and a useful check on the face validity of our statistical method.

To present these estimates, Figure 5 provides point estimates and $90 \%$ CIs for each of the online news media in our data. Well-known moderate and extreme news media organizations are bolded for reference. As the data show, estimates of the ideology of news media organizations are in alignment with what observers of US politics and media would expect. Social media users sharing behavior, in other words, maps extremely well on to what we would intuit would be the rank ordering and relative distances between news media organizations. For instance, Breitbart News, the news organization prominent during the 2016 US presidential election is to the right of Fox News, which is to the right of the Wall Street Journal, the establishment center-right daily paper. On the left, the orderings have similar face validity. ThinkProgress and HuffPost, for example, are to the left of the center-left New York Times, Washington Post, and CNN. Finally, the news wire services Reuters and Associated Press find themselves in the center ideologically. As would be expected, the estimates are more precise for more popular outlets shared by more people. $^{22}$

from the $115^{\text {th }}$ Congress (that used herein), these correlations are $\rho_{\mathrm{D}}^{\text {(senate) }}=0.57$, and $\rho_{\mathrm{R}}^{\text {(senate) }}=0.54, \rho_{\mathrm{D}}^{\text {(house) }}=0.47$, and $\rho_{\mathrm{R}}^{\text {(house) }}=0.34$. Estimates using Twitter following data for the $115^{\text {th }}$ Congress are estimated by the authors, with estimation details provided in the Supplementary Material.

${ }^{22}$ In Appendix B we show the estimated values of the $\omega_{m}$ parameters for each news domain. We see larger values for the larger, mainstream media sites such as New York Times and Fox News, suggesting that they are shared by more 


\section{Figure 5: Ideology of Online News Media}

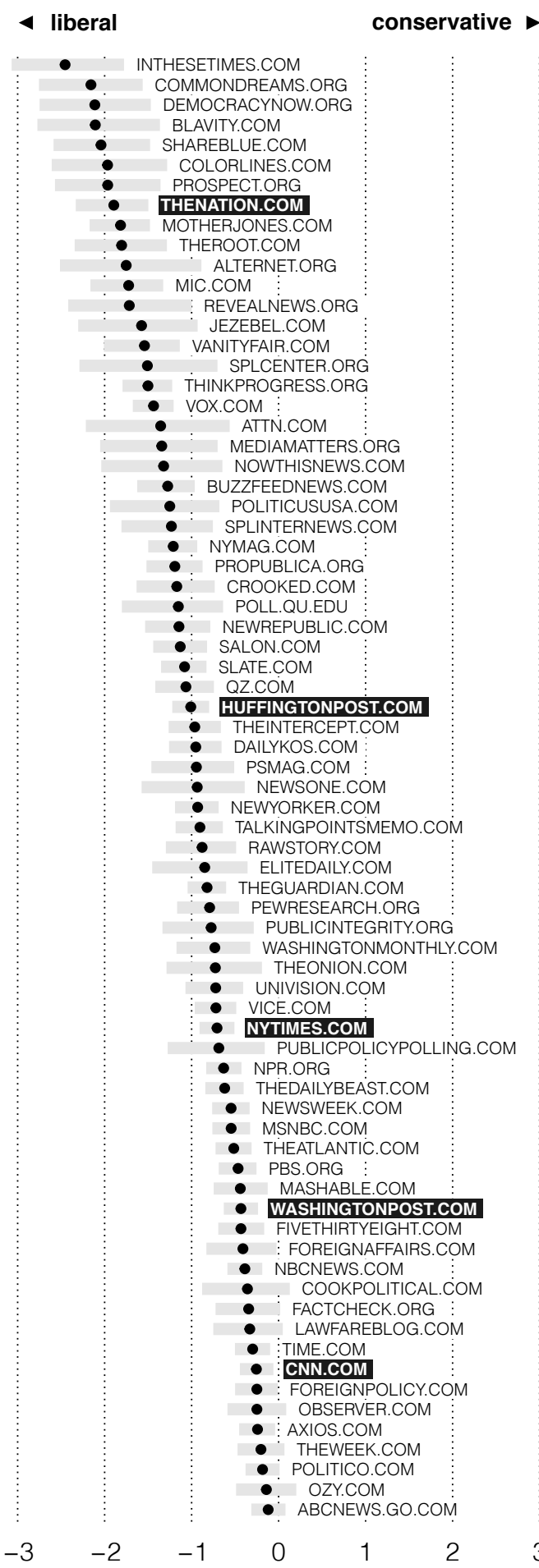

4 liberal

: VOANEWS.COM

$\vdots$ IBTIMES.COM

ECONOMISTCOM

DAILYDOT.COM

:FORTUNE.COM

MEDIAITE.COM

CBSNEWS .COM

TASKANSMONITOR.COM

POLITIFACTCOM

APNEWS.COM

MCCLATCHYDC COM

USATODAY.COM

HBR.ORG

BUSINESSINSIDER.COM

: ROLLCALL.COM

YAHOO.COM/NEWS

THEHILL.COM

BLOOMBERG.COM

GOVERNING.COM

USNEWS.COM

STRIPES.COM

C-SPAN.ORG

RT.COM
NATIONALJOURNAL.COM

FORBES.COM

MORNINGCONSULT.COM

CNBC.COM

UPI.COM
NYPOST.COM

NYPOST.COM

WSJ.COM

RASMUSSENREPORTS.COM

REASON.COM

THEEPOCHTIMES.COM

REALCLEARPOLITICS.COM

NATIONALINTEREST.ORG

FULLMEASURE.NEWS

EXAMINER.COM

WEEKGTANTMES.COM

: NEWSMAX.COM

COMMENTARYMAGAZINE.COM
$\vdots$

HOTAIR.COM:

WESTERNJOURMEDIA.COM

RARE US

TWITCHYCOM

FOXBUSINESS COM

NATIONALREVIEW.COM

CBN.COM/CBNNEWS

FREEBEACON.COM

THEFEDERALIST.COM

DAILYWIRE.COM

TOWNHALL.COM

DAILYCALLER.COM

CNSNEWS.COM

THERESURGENT.COM

BREITBART.COM

REDSTATE.COM

DAILYSIGNAL.COM

LIFEZETTĖ.COM

THEBLAZE.COM

SPECTATOR.ORG

WND.COM
AMERICANTHINKER.COM

NEWSBUSTERS.ORG

CONSERVATVREVI

IVEREV

O

$\begin{array}{ll}0 & 1\end{array}$

2

3

Media score ( $\zeta)$

This figure presents the estimated ideology of online news media organizations as estimated from the sharing behavior of social media users. Media names in black simply indicate a few well-known media organizations across the political spectrum. 
Figure 6: Density of the Ideology of Online News Media

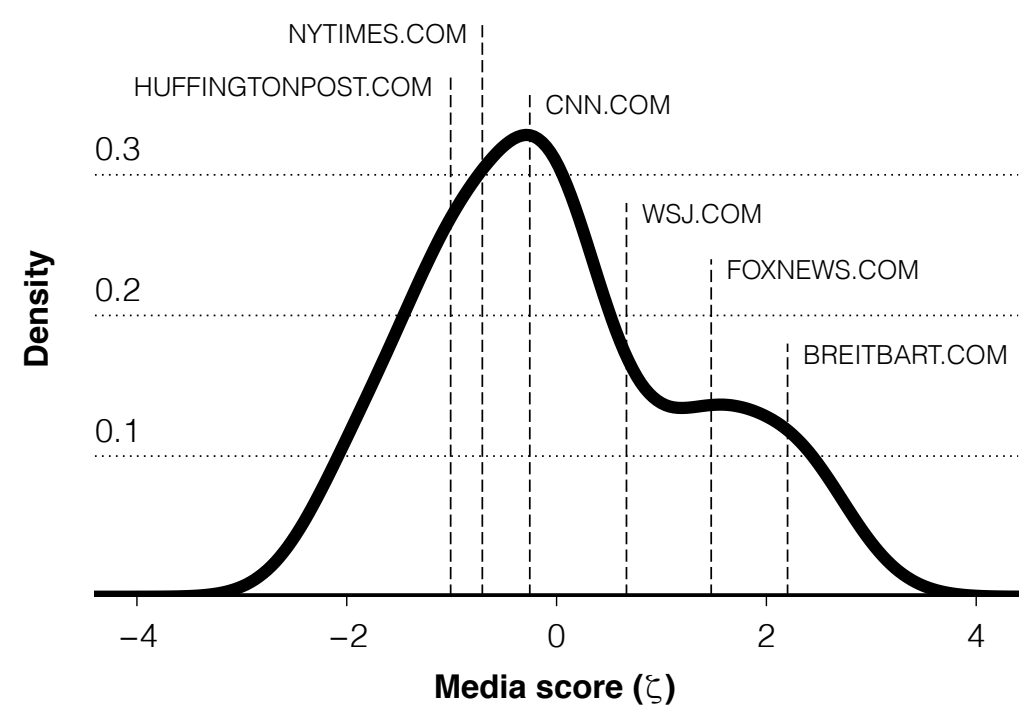

This figure presents a density plot of the estimated ideology of online news media organizations as estimated from the sharing behavior of social media users.

To examine the ideological distribution of online news media, Figure 6 presents the density of news media outlets online. As expected, given the ideological polarization of the electorate and that which is perceived by commentators on news media in the United States, the graph clearly shows a bi-modal distribution, with many more liberal news outlets on the left, and a smaller but meaningful group of conservative media on the right.

\section{Legislators, Citizens, and the Ideological Polarization of News Sharing}

Having established the validity of Media-Sharing scores, we now use them to examine several substantive questions. Among the most important questions in the study of online political behavior are those concerning the level, and consequences, of polarization, especially as it pertains to political discourse and information sharing (e.g. Bakshy, Messing and Adamic, 2015; Barberá, 2015b; Boxell, Gentzkow and Shapiro, 2017; Bail et al., 2018). We first consider the question of whether members of congress or the mass public are more polarized in their sharing of news material online (i.e., which group shares more ideologically extreme material). 
For political behavior in traditional offline arenas such as voting behavior in Congress, research has demonstrated that Members of Congress are both heavily polarized ideologically and have become more so over time (McCarty, Poole and Rosenthal, 2006; Fiorina and Abrams, 2009; Hetherington, 2009; Hare and Poole, 2014; Gentzkow, Shapiro and Taddy, 2019). The literature is less clear on trends in polarization among the general public (e.g. Abramowitz, 2010; Hill and Tausanovitch, 2015; Abramowitz, 2018; Kinder and Kalmoe, 2017; Campbell, 2018). Research has concluded nevertheless, that legislators in the US are substantially more ideologically polarized than is the electorate (Bafumi and Herron, 2010; Hetherington, Long and Rudolph, 2016). ${ }^{23}$

However, whether the political behavior of citizens and politicians online matches these conventional (offline) differences in ideological polarization is unknown. On the one hand, it may be the case that online political behavior naturally aligns with political attitudes and behaviors offline. On the other hand, as Tausanovitch and Warshaw (2017) show, the ideological presentation and measurement of attitudes and behaviors in one political context do not necessarily map well on to analogous measures using attitudes and behaviors in another. Communication of ideological positioning, in other words, is likely to vary across contexts and behaviors for theoretically meaningful reasons. For example, the constraints and incentives for how legislators vote on bills in Congress have been shown to differ from the constraints they face when those legislators discuss their positions on those same bills with constituents (e.g. Grimmer, 2013a,b; Cormack, 2016).

Yet despite the importance of understanding differences between the online behaviors of politicians and ordinary citizens, our empirical understanding of these differences is relatively weak. This is in part because existing approaches have tended to rely on ordinary users' ideological perceptions of political elites to draw comparisons between ordinary social media

\footnotetext{
${ }^{23}$ The measurement of citizens and politicians on a common ideological scale is a perennial challenge in the study of politics. One strategy is to ask survey respondents to 'vote' on bills that have already been voted on by Members of Congress, providing a empirical bridge between the behavior of legislators and ordinary citizens. With respect to polarization, however, this strategy may be problematic. Hill and Huber (2019) show, for example, that when contextual information is given to respondents about each bill—information that would be known to legislators when voting - they exhibit much more polarization.
} 
Figure 7: Ideology of ordinary users and Members of Congress as estimated by Facebook endorsement (Bond and Messing, 2015) and Twitter following data (Barberá, 2015a)

A. Facebook endorsement data

(Bond \& Messing 2015)

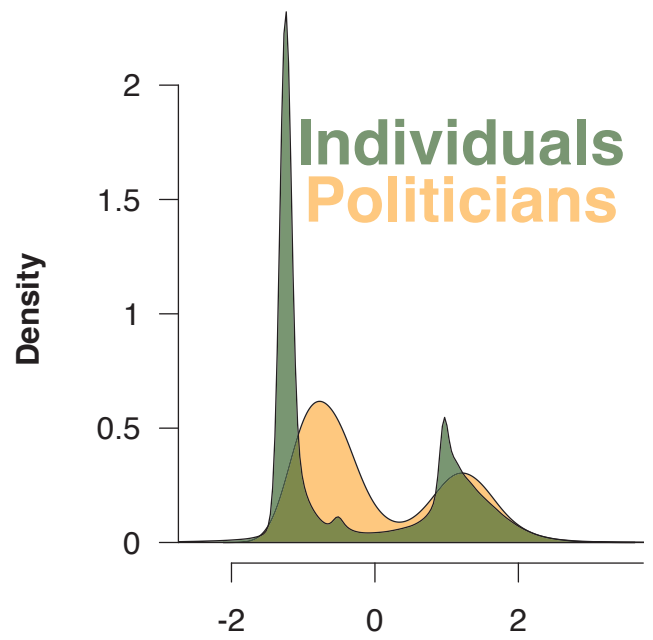

Facebook ideology score
B. Twitter follower data

(Barberá 2015)

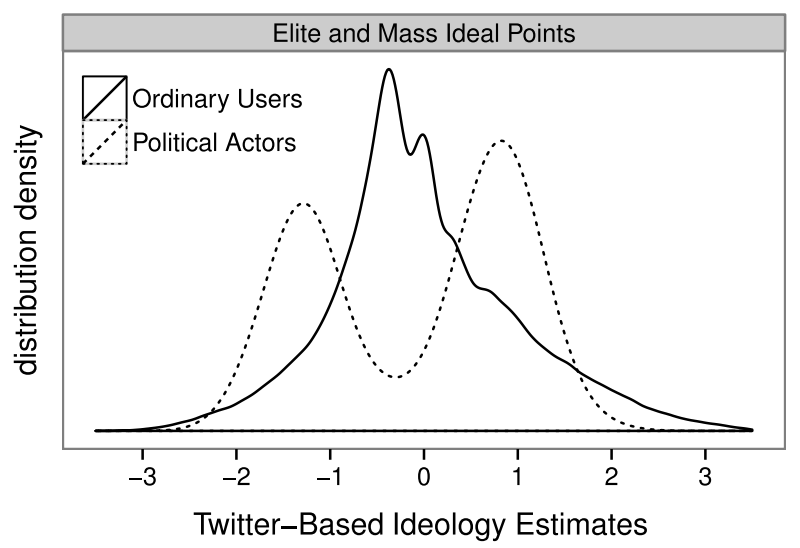

C. News media sharing (Mediascores)

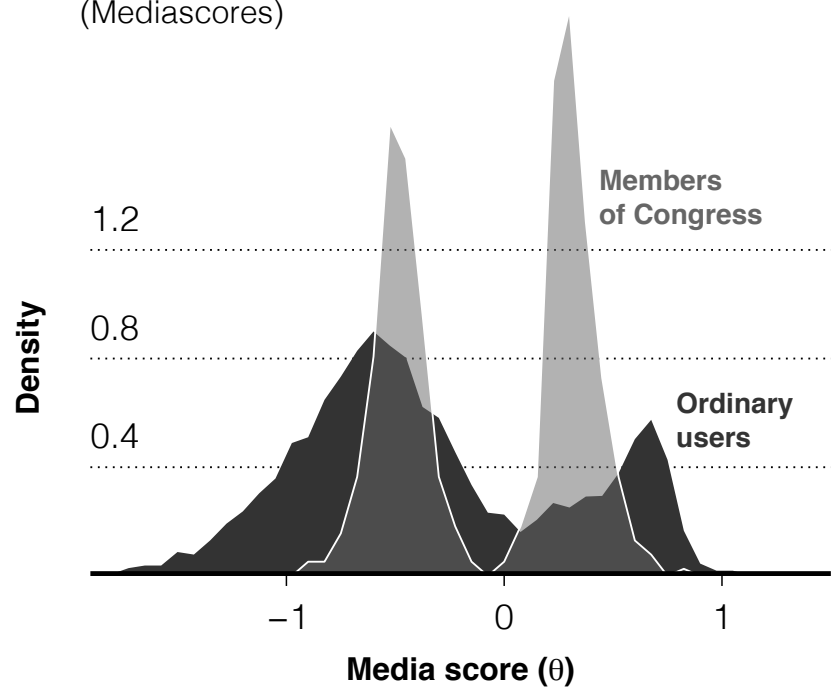

This figure presents estimates of the ideology of ordinary users and Members of Congress as estimated by Bond and Messing (2015) using Facebook 'endorsement' data (left panel), and Barberá (2015a) using Twitter 'following' data (right panel). Figures reproduced directly from Bond and Messing (2015) and Barberá (2015a).

users and politicians. Bond and Messing (2015) and Barberá (2015a), for instance, use the endorsement and following behaviors of users to estimate the ideology of politicians to make such comparisons. ${ }^{24}$ In Figure 7 we present the distributions generated by the authors from the

${ }^{24}$ These approaches are roughly analogous to the use of ideological placement scales to estimate the locations of 
two respective methods. Interestingly, the ideological distributions estimated from endorsement and following behavior are substantially different: on Facebook, for example, Bond and Messing (2015) find mixed evidence concerning the relative polarization of users and politicians; Barberá (2015a), by contrast, finds that users on Twitter are substantially more moderate than politicians. However, because we use estimate a measure of ideology that is based on data and behavior that are shared by both sets of actors-ordinary users and politicians-we can examine ideological polarization in online information sharing without relying on users' perceptions of political actors. To show the comparison across the two groups, we graph the ideological distributions of Members of Congress and ordinary users jointly in Figure 7. We see that the ideological distributions of ordinary users and politicians are bi-modal, with clear separation between modes for both sets of actors. The news sharing behavior of Members of Congress and ordinary users, in other words, is highly polarized. Unlike the conventional expectation of a set of legislators that is more polarized the citizenry, we see instead that the distribution of users is more polarized than that of politicians. The gap between the modes of the distribution for the public is larger than the gap between the two modes for members of Congress. And the rather large tails of the distribution of the public sit outside the distribution of members of Congress on both the left and right side of the distributions: a large proportion of users is estimated to be to the left of Democratic Members of Congress (the left mode) and a smaller but substantial set of users to the right of Republican Members (right mode). With respect to the news-sharing, a common behavior across social media users and politicians, the ideological presentation of users is substantially more polarized.

Interestingly, while ordinary users on the left appear less polarized relative to Members of Congress, those on the right appear much more so. Put differently, among those on the left, the most frequent sharers of political news are relatively moderate; among those on the right, they are much more polarizing.

politicians and survey respondents on a common scale (e.g. Hare et al., 2015; Saiegh, 2015; Ramey, 2016). 


\subsection{Communicating Partisanship and Moderation in News Sharing}

Above, we demonstrated that the ideology of politicians based on their news-sharing behavior is less polarized than that of ordinary users. What explains, however, variation in news-sharing among political representatives themselves? Answering this question is important because it highlights a key distinction between the behaviors of legislators as it relates to formal policymaking (voting) and that as it relates to how legislators communicate their policies, attitudes, and goals to the public.

Furthermore, as Barberá and Zeitzoff (2018) show, politicians are increasingly using social media to communicate with the public both during and outside of election campaigns. As others have shown, politicians communicate with their constituents in ways that differ depending on factors independent of their voting behavior. Grimmer (2013a) shows, for example, that legislators in districts with a large proportion of constituents who are co-partisans tend to emphasize their positions on the issues, whereas those in more heterogeneous districts tend to emphasize appropriations to avoid alienating those on the other side of a given issue. Cormack (2016) shows, moreover, that legislators are highly selective in the votes that they emphasize in their written communications to voters. Using a large dataset of newsletters sent to constituents, she shows that legislators in districts containing many co-partisans choose to highlight more ideologically extreme votes than legislators in districts with a more uniform mix of co-partisans to other-partisans.

Building on this work, we examine whether differences in the partisan make-up of legislators' districts affect how moderate or extreme the media is that they share with the public on social media. Do the communication strategies of politicians on social media reflect electoral constraints of the political composition of the audience who elects them?

To investigate this, we test whether the degree of partisan alignment in each Member of Congress's congressional district or state is associated with how moderate or extreme their news information sharing is online. Our expectation is that politicians who face stiffer competition in a general election will be less likely to share polarizing news media. This is because politicians in 
competitive general elections will be much more wary of distancing themselves from moderate voters who may be decisive in a general election. By contrast, politicians in less competitive districts or states are expected to be less ideologically constrained with respect to moderate voters, and thus freer to express stronger ideological leanings. Furthermore, politicians who benefit from less competitive general elections can be expected to be more fearful of primary election challengers from their ideologically flanks. This creates an incentive to appeal to primary voters through political communication that emphasizes the ideological leanings of co-partisan primary voters.

To test this, we measure district and state partisan alignment by the difference in the vote share of Donald Trump and Hillary Clinton during the 2016 US presidential election in each district/state. This measure is similar to that used by Grimmer (2013a) to examine partisan alignment and the use of position-taking and appropriations in legislators' (offline) political communication. For Democratic Members of Congress, we reverse this measure such that high values for all politicians indicate a partisan gap favorable to each legislator, and low values indicate a less favorable local partisan context. Empirically, therefore, we expect that the higher (more favorable) the partisan gap in a legislator's district (congresspersons) or state (Senators), the more likely they will be to exhibit more ideologically extreme information-sharing.

To demonstrate our results, we begin by presenting graphically in Figure 8 the relationship between the information-sharing ideology of Members of Congress and the partisan gap of each members' district or state (as labeled by the party of each politician). The upward and downward sloping lines represent linear regression models fit to the data from Republicans and Democrats respectively. Consistent with our expectations, as the partisan alignment of a Member of Congress's district or state increases, so too does the ideological extremeness of their information-sharing, with similar changes in information-sharing ideology between Republicans and Democrats.

To examine this more systematically, we fit OLS regression models to our data. Our response variable is the information-sharing ideology of each Member of Congress, and our independent 
Figure 8: News sharing ideology and the district/state alignment of Members of Congress

- Democrat o Republican

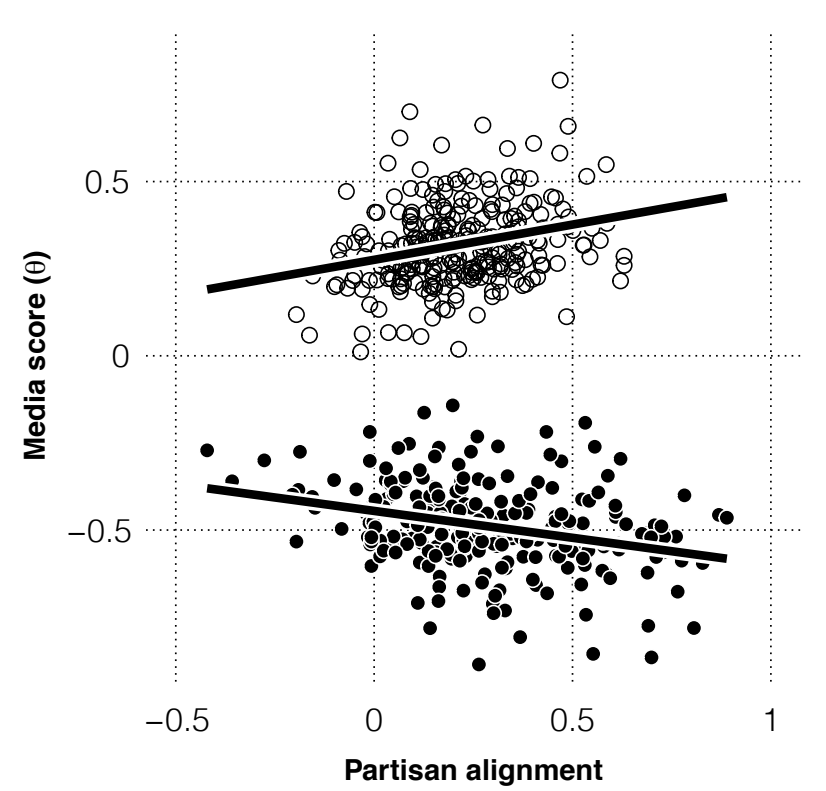

This figure shows the partisan alignment of the state or district that each Senator and Congressperson represents and their news sharing behavior as measured by their Media Score. Each line demonstrates the bivariate relationship between district/state alignment and news sharing, as estimated separately per party.

variable of interest is the partisan alignment of each district or state. Results are presented in Table 2. In the first model, we present the simple bivariate relationship between partisan alignment and information-sharing ideology. As expected, the results show that as partisan alignment increases, the extremeness of each Member of Congress's sharing ideology does also $(\mathrm{p}<0.001)$.

But does this pattern hold even if we account for traditional behavioral measures of legislator ideology? To investigate this, Models (3) and (4) include as a covariate the roll-call voting ideology of each Member of Congress as measured by their NOMINATE scores. As the results of these models in Table 2 show, even when accounting for the ideology of legislators' voting records, politicians who represent districts or states with higher partisan alignment exhibit more ideologically extreme information-sharing behavior online $(\mathrm{p}<0.01)$.

Our results thus suggest that politicians' information-sharing strategies on social media are, in part, driven by local electoral constraints specific to each legislator's district. Consistent 
Table 2: The relationship between news sharing ideology and district/state partisan composition

\begin{tabular}{|c|c|c|c|c|}
\hline & \multicolumn{4}{|c|}{$\begin{array}{c}\text { Extremism of } \\
\text { news sharing ideology }\end{array}$} \\
\hline & (1) & (2) & (3) & (4) \\
\hline Alignment & $\begin{array}{c}0.146^{* * *} \\
(0.020)\end{array}$ & $\begin{array}{c}0.159^{* * *} \\
(0.022)\end{array}$ & $\begin{array}{c}0.051^{* *} \\
(0.023)\end{array}$ & $\begin{array}{c}0.058^{* *} \\
(0.023)\end{array}$ \\
\hline House member & & $\begin{array}{l}-0.011 \\
(0.011)\end{array}$ & $\begin{array}{l}-0.006 \\
(0.010)\end{array}$ & $\begin{array}{l}-0.003 \\
(0.010)\end{array}$ \\
\hline NOMINATE & & & $\begin{array}{c}0.381^{* * *} \\
(0.052)\end{array}$ & $\begin{array}{l}-0.013 \\
(0.195)\end{array}$ \\
\hline NOMINATE $^{2}$ & & & & $\begin{array}{l}0.487^{* *} \\
(0.234)\end{array}$ \\
\hline Republican $\times$ NOMINATE & & & $\begin{array}{l}-0.083 \\
(0.060)\end{array}$ & $\begin{array}{c}0.098 \\
(0.254)\end{array}$ \\
\hline Republican $\times$ NOMINATE ${ }^{2}$ & & & & $\begin{array}{l}-0.277 \\
(0.284)\end{array}$ \\
\hline Republican & & $\begin{array}{l}0.017^{* *} \\
(0.008)\end{array}$ & $\begin{array}{c}0.007 \\
(0.025)\end{array}$ & $\begin{array}{l}-0.016 \\
(0.056)\end{array}$ \\
\hline Intercept & $\begin{array}{c}-0.034^{* * *} \\
(0.006)\end{array}$ & $\begin{array}{c}-0.037^{* * *} \\
(0.011)\end{array}$ & $\begin{array}{c}-0.156^{* * *} \\
(0.019)\end{array}$ & $\begin{array}{c}-0.088^{* *} \\
(0.038)\end{array}$ \\
\hline $\mathrm{N}$ & 499 & 499 & 499 & 499 \\
\hline
\end{tabular}

with the findings of Grimmer (2013a) and Cormack (2016), politicians use social media as a communications platform to selectively emphasize information to appeal either to a local partisan audience or to a general one: whereas legislators with highly partisan-aligned audiences emphasize ideologically extreme information online, those with mixed audiences emphasize more moderate content.

\section{Conclusion}

Research into the attitudes and behaviors of politicians and users on social media has expanded rapidly in recent years. Much of this literature focuses on either the behaviors or discourse of political actors or that of users. In this article, we provide a means to analyze the ideological foundations of the behaviors of politicians and users jointly by focusing on news media link sharing, a mode of information sharing common to both sets of actors. The examination of 
Figure 9: Amount of National News Shared by Members of Congress (by media score)

- Democrat o Republican

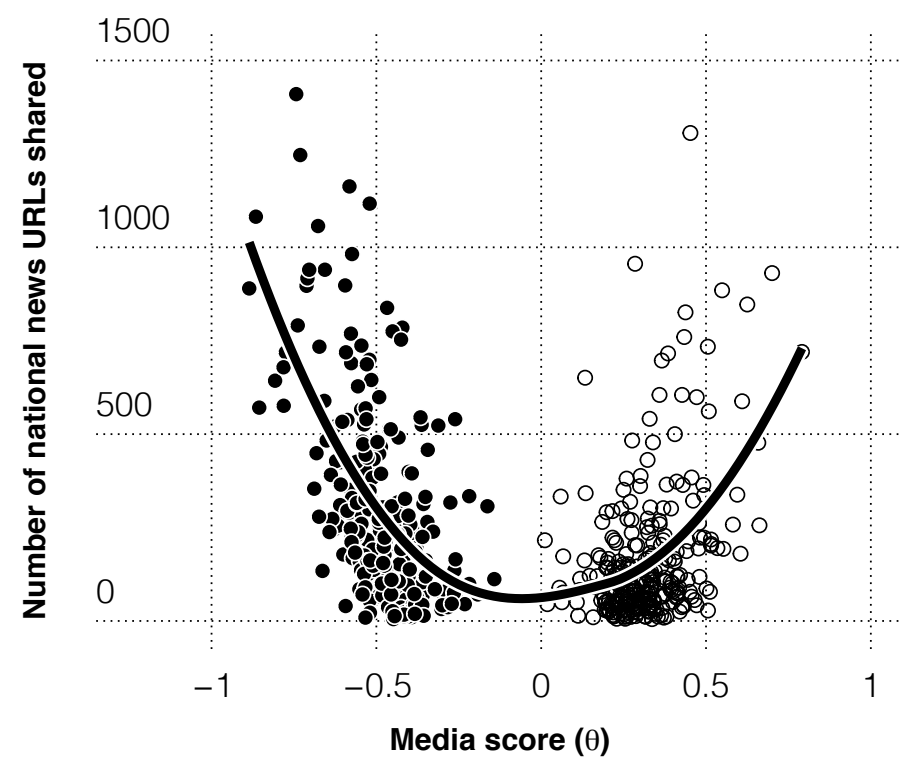

This figure shows the frequency of national news media shared by Members of Congress and the ideology of the sharer. The line in black represents a LOESS regression line to demonstrate the relationship being national news sharing and political ideology.

these information-sharing behaviors is central to a wide set of questions in political science, and our approach opens up a number of lines of inquiry for future research. Does the ideological extremeness of information-sharing change among the public and politicians during election campaigns? Is the sharing by politicians during primary elections more polarized than that during general elections? What is the ideological presentation of accounts controlled by foreign governments who seek to intervene in democratic elections? Do political events shape who shares news and from what sources? Does the ideology of news sharing vary across social media platforms? What do the links to video channels (e.g. YouTube) on social media tell us about the users who share them and the channels themselves? In future research, we hope the approach introduced in this article will provide researchers with the tools to help answer these and similar questions concerning political information-sharing online. 


\section{References}

Abramowitz, Alan I. 2010. The Disappearing Center. New Haven, CT: Yale University Press.

Abramowitz, Alan I. 2018. The Great Alignment: Race, Party Transformation, and the Rise of Donald Trump. New Haven, CT: Yale University Press.

Aldrich, John H. and Richard D. McKelvey. 1977. "A Method of Scaling with Applications to the 1968 and 1972 Presidential Elections.” American Political Science Review 71(1):111-130.

Bafumi, Joseph, Andrew Gelman, David K. Park and Noah Kaplan. 2005. "Practical Issues in Implementing and Understanding Bayesian Ideal Point Estimation.” Political Analysis 13(2):171-187.

Bafumi, Joseph and Michael C. Herron. 2010. "Leapfrog Representation and Extremism: A Study of American Voters and Their Members in Congress." American Political Science Review 104(3):519-542.

Bail, Christopher, Lisa Argyle, Taylor Brown, John Bumpus, Haohan Chen, M. B. Fallin Hunzaker, Jaemin Lee, Marcus Mann, Friedolin Merhout and Alexander Volfovsky. 2018. “Exposure to Opposing Views can Increase Political Polarization: Evidence from a Large-Scale Field Experiment on Social Media." Proceedings of the National Academy of Sciences 115(37):92169221.

Bakshy, Eytan, Solomon Messing and Lada A. Adamic. 2015. "Exposure to Ideologically Diverse News and Opinion on Facebook.” Science 348(6239):1130-1132.

Barberá, Pablo. 2015a. "Birds of the Same Feather Tweet Together: Bayesian Ideal Point Estimation Using Twitter Data.” Political Analysis 23(1):76-91.

Barberá, Pablo. 2015b. "How Social Media Reduces Mass Political Polarization: Evidence from Germany, Spain, and the U.S.” Unpublished manuscript, 1-46.

Barberá, Pablo, Andreu Casas, Jonathan Nagler, Patrick J. Egan, Richard Bonneau, John T. Jost and Joshua A. Tucker. 2019. "Who Leads? Who Follows? Measuring Issue Attention and Agenda 
Setting by Legislators and the Mass Public Using Social Media Data.” American Political Science Review 113(4):883-901.

Barberá, Pablo and Thomas Zeitzoff. 2018. “The New Public Address System: Why Do World Leaders Adopt Social Media?” International Studies Quarterly62(1):121-130.

BBC News. 2017. “Obama Warns Against Irresponsible Social Media Use.” BBC News, December 27.

Bertrand, Marianne and Emir Kamenica. 2018. "Coming Apart? Cultural Distances in the United States Over Time.” NBER Working Paper No. 24771, June.

Boche, Adam, Jeffrey B. Lewis, Aaron Rudkin and Luke Sonnet. 2018. “The New Voteview.com: Preserving and Continuing Keith Poole's Infrastructure for Scholars, Students and Observers of Congress." Public Choice 176(1):17-32.

Bond, Robert and Solomon Messing. 2015. “Quantifying Social Media’s Political Space: Estimating Ideology from Publicly Revealed Preferences on Facebook.” American Political Science Review 109(1):62-78.

Bonica, Adam. 2013. "Ideology and Interests in the Political Marketplace.” American Journal of Political Science 57(2):294-311.

Bonica, Adam. 2014. “Mapping the Ideological Marketplace.” American Journal of Political Science 58(2):367-386.

Bonica, Adam. 2018. “Inferring Roll-Call Scores from Campaign Contributions Using Supervised Machine Learning." American Journal of Political Science 62(4):830-848.

Bonica, Adam and Maya Sen. 2017. "A Common-Space Scaling of the American Judiciary and Legal Profession.” Political Analysis 25(1):114-121.

Bonica, Adam and Michael J. Woodruff. 2015. "A Common-Space Measure of State Supreme Court Ideology.” The Journal of Law, Economics, and Organization 31(3):472-498.

Boutet, Antoine, Hyoungshick Kim and Eiko Yoneki. 2012. "What's in Your Tweets? I Know Who You Supported in the UK 2010 General Election." Association for the Advancement of Artificial 


\section{Intelligence.}

Boxell, Levi, Matthew Gentzkow and Jesse M. Shapiro. 2017. "Greater Internet Use is Not Associated with Faster Growth in Political Polarization among US Demographic Groups.” Proceedings of the National Academy of Sciences 114(40):10612-10617.

Budak, Ceren, Sharad Goel and Justin M. Rao. 2016. "Fair and Balanced? Quantifying Media Bias through Crowdsourced Content Analysis.” Public Opinion Quarterly 80(S1):250-271.

Campbell, James E. 2018. Polarized. Princeton, NJ: Princeton University Press.

Carpenter, Bob, Andrew Gelman, Matt D. Hoffman, Daniel Lee, Ben Goodrich, Michael Betancourt, Marcus A. Brubaker, Jiqiang Guo, Peter Li and Allen Riddell. 2017. "Stan: A Probabilistic Programming Language.” Journal of Statistical Software 76(1):1-32.

Clinton, Joshua D., Simon Jackman and Douglas Rivers. 2004. “The Statistical Analysis of Roll Call Data." American Political Science Review 98(2):355-370.

Cohen, Raviv and Derek Ruths. 2013. “Classifying Political Orientation on Twitter: It’s Not Easy!” Proceedings of the Seventh International AAAI Conference on Weblogs and Social Media, 91-99. Conover, Michael D., Bruno Gonçalves, Jacob Ratkiewicz, Alessandro Flammini and Filippo Menczer. 2011. "Predicting the Political Alignment of Twitter Users." Proceedings of the International Conference on Social Computing.

Cormack, Lindsey. 2016. “Extremity in Congress: Communications versus Votes.” Legislative Studies Quarterly 41(3):575-603.

Crosson, Jesse M., Alexander C. Furnas and Geoffrey M. Lorenz. Forthcoming. "Polarized Pluralism: Organizational Preferences and Biases in the American Pressure System." American Political Science Review pp. 1-45.

Eady, Gregory and Peter Loewen. Forthcoming. "Measuring Uncertainty about Candidate Ideology: An Application to US Presidential Elections.” Journal of Politics pp. 1-32.

Facebook \& Social Science One. 2018. “Facebook URL Shares Dataset.” Requests for Proposals: Social Media and Democracy Research Grants, July 11. 
Fiorina, Morris P. and Samuel J. Abrams. 2009. Disconnect: The Breakdown of Representation in American Politics. Norman, OK: University of Oklahoma Press.

Gelman, Andrew, John B. Carlin, Hal S. Stern, David B. Dunson, Aki Vehtari and Donald B. Rubin. 2014. Bayesian Data Analysis. 3rd ed. Boca Raton, FL: CRC Press: Taylor \& Francis Group.

Gentzkow, Matthew and Jesse M. Shapiro. 2010. "What Drives Media Slant? Evidence from U.S. Daily Newspapers.” Econometrica 78(1):35-71.

Gentzkow, Matthew and Jesse M. Shapiro. 2011. “Ideological Segregation Online and Offline.” Quarterly Journal of Economics 126(3):1799-1839.

Gentzkow, Matthew, Jesse M. Shapiro and Matt Taddy. 2019. "Measuring Group Differences in High-Dimensional Choices: Method and Application to Congressional Speech.” Econometrica 87(4):1307-1340.

Grimmer, Justin. 2013a. “Appropriators not Position Takers: The Distorting Effects of Electoral Incentives on Congressional Representation.” American Journal of Political Science 57(3):624642.

Grimmer, Justin. 2013b. Representational Style in Congress: What Legislators Say and Why it Matters. New York, NY: Cambridge University Press.

Grinberg, Nir, Kenneth Joseph, Lisa Friedland, Briony Swire-Thompson and David Lazer. 2019.

“Fake News on Twitter during the 2016 U.S. Presidential Election.” Science 363:374-378.

Groseclose, Tim and Jeffrey Milyo. 2005. “A Measure of Media Bias.” The Quarterly Journal of Economics CXX(4):1191-1237.

Groseclose, Tim, Steven D. Levitt and James M. Snyder Jr. 1999. “Comparing Interest Group Scores across Time and Chambers: Adjusted ADA Scores for the U.S. Congress." American Political Science Review 93(1):33-50.

Hare, Christopher, David A. Armstrong II, Ryan Bakker, Royce Carroll and Keith T. Poole. 2015. “Using Bayesian Aldrich-McKelvey Scaling to Study Citizens' Ideological Preferences and Perceptions.” American Journal of Political Science 59(3):759-774. 
Hare, Christopher and Keith T. Poole. 2014. “The Polarization of Contemporary American Politics.” Polity 46(3):411-429.

Heckman, James J. and James M. Snyder Jr. 1997. "Linear Probability Models of the Demand for Attributes with an Empirical Application to Estimating the Preferences of Legislators.” RAND Journal of Economics 28(0):S142-S189.

Herrman, John and Mike Isaac. 2016. “Conservatives Accuse Facebook of Political Bias.” New York Times, May 9.

Hetherington, Marc J. 2009. “Putting Polarization in Perspective.” British Journal of Political Science 39(2):413-448.

Hetherington, Marc J., Meri T. Long and Thomas J. Rudolph. 2016. "Revisiting the Myth: New Evidence of a Polarized Electorate.” Public Opinion Quarterly 80(S1):321-350.

Hill, Seth J. and Chris Tausanovitch. 2015. "A Disconnect in Representation? Comparison of Trends in Congressional and Public Polarization.” Journal of Politics 77(4):1058-1075.

Hill, Seth J. and Gregory A. Huber. 2019. “On the Meaning of Survey Reports of Roll Call “Votes”.” American Journal of Political Science 63(3):611-625.

Ho, Daniel E. and Kevin M. Quinn. 2008. "Measuring Explicit Political Positions of Media.” Quarterly Journal of Political Science 3(4):353-377.

Jackman, Simon. 2001. "Multidimensional Analysis of Roll Call Data via Bayesian Simulation: Identification, Estimation, Inference, and Model Checking.” Political Analysis 9(3):227-241.

Jessee, Stephen. 2016. “(How) Can We Estimate the Ideology of Citizens and Political Elites on the Same Scale?” American Journal of Political Science 60(4):1108-1124.

Jessee, Stephen A. 2009. “Spatial Voting in the 2004 Presidential Election.” American Political Science Review 103(1):59-81.

Jessee, Stephen and Neil Malhotra. 2013. "Public (Mis)perceptions of Supreme Court Ideology: A Method for Directly Comparing Citizens and Justices.” Public Opinion Quarterly 77(2):619-634. Kang, Cecilia, Tiffany Hsu, Kevin Roose, Natasha Singer and Matthew Rosenberg. 2018. “Mark 
Zuckerberg Testimony: Day 2 Bring Tougher Questioning.” New York Times, April 11.

Kinder, Donald R. and Nathan P. Kalmoe. 2017. Neither Liberal nor Conservative: Ideological Innocence in the American Public. Chicago, IL: University of Chicago Press.

Kteily, Nour S., Matthew D. Rocklage, Kaylene McClanahan and Arnold K. Ho. 2019. “Political Ideology Shapes the Amplification of the Accomplishments of Disadvantaged vs. Advantaged Group Members.” Proceedings of the National Academy of Sciences 116(5):1559-1568.

Lauderdale, Benjamin E. 2010. “Unpredictable Voters in Ideal Point Estimation.” Political Analysis 18(2):151-171.

Lauderdale, Benjamin E. and Alexander Herzog. 2016. "Measuring Political Positions from Legislative Speech.” Political Analysis 24(3):374-394.

Martin, Andrew D. and Kevin M. Quinn. 2002. "Dynamic Ideal Point Estimation via Markov Chain Monte Carlo for the U.S. Supreme Court, 1953-1999.” Political Analysis 10(2):134-153.

Martin, Gregory J. and Ali Yurukoglu. 2017. "Bias in Cable News: Persuasion and Polarization.” American Economic Review 107(9):2565-2599.

Martin, Gregory J. and Josh McCrain. 2019. “Local News and National Politics.” American Political Science Review 113(2):372-384.

McCarty, Nolan, Keith Poole and Howard Rosenthal. 2006. Polarized America: The Dance of Inequality and Unequal Riches. Cambridge, MA: MIT Press.

McKay, Amy. 2008. "A Simple Way of Estimating Interest Group Ideology.” Public Choice 136(12):69-86.

McPherson, Miller, Lynn Smith-Lovin and James M. Cook. 2001. "Birds of a Feather: Homophily in Social Networks.” Annual Review of Sociology 27:415-444.

Messing, Solomon, Patrick van Kessel and Adam Hughes. 2017. "Sharing the News in a Polarized Congress: Partisan and Ideological Divides Shape Which News Outlets Legislators Share Links to on Facebook." Pew Research Center, December 17.

Peterson, Andrew and Arthur Spirling. 2018. "Classification Accuracy as a Substantive Quantity 
of Interest: Measuring Polarization in Westminster Systems.” Political Analysis 26(1):120-128.

Pew Research Center. 2014. "Political Polarization \& Media Habits: From Fox News to Facebook, How Liberals and Conservatives Keep Up with Politics." October 21.

Poole, Keith and Howard Rosenthal. 1985. "A Spatial Model for Legislative Roll Call Analysis." American Journal of Political Science 29(2):357-384.

Poole, Keith T. 2005. Spatial Models of Parliamentary Voting. New York, NY: Cambridge University Press.

Preoţiuc-Pietro, Daniel, Ye Liu, Daniel J. Hopkins and Lyle Ungar. 2017. “Beyond Binary Labels: Political Ideology Prediction of Twitter Users.” Proceedings of the 55th Annual Meeting of the Association for Computational Linguistics, 729-740.

Prior, Markus. 2007. Post-Broadcast Democracy: How Media Choice Increases Inequality in Political Involvement and Polarizes Elections. Cambridge, UK: Cambridge University Press.

Ramey, Adam. 2016. “Vox Populi, Vox Dei? Crowdsourced Ideal Point Estimation.” Journal of Politics 78(1):281-295.

Richardson, Mark D., Joshua D. Clinton and David E. Lewis. 2018. “Elite Perceptions of Agency Ideology and Workforce Skill.” Journal of Politics 80(1):303-308.

Saiegh, Sebastián M. 2015. "Using Joint Scaling Methods to Study Ideology and Representation: Evidence from Latin America.” Political Analysis 23(3):363-384.

Shearer, Elisa. 2019. “Social Media Outpaces Print Newspapers in the U.S. as a News Source.” Pew Research Center, December 10.

Slapin, Jonathan B. and Sven-Oliver Proksch. 2008. "A Scaling Model for Estimating Time-Series Party Positions from Texts.” American Journal of Political Science 52(3):705-722.

Tausanovitch, Chris and Christopher Warshaw. 2014. "Representation in Municipal Government." American Political Science Review 108(3):605-641.

Tausanovitch, Chris and Christopher Warshaw. 2017. “Estimating Candidates' Political Orientation in a Polarized Congress.” Political Analysis 25(2):167-187. 
Temporão, Michael, Corentin Vande Kerckhove, Clifton van der Linden, Yannick Dufresne and Julien M. Hendrickx. 2018. “Ideological Scaling of Social Media Users: A Dynamic Lexicon Approach.” Political Analysis 26(4):457-473.

Theocharis, Yannis, Pablo Barberá, Zoltán Fazekas, Sebastian Adrian Popa and Olivier Parnet. 2016. “A Bad Workman Blames His Tweets: The Consequences of Citizens' Uncivil Twitter Use When Interacting with Party Candidates." Journal of Communication 66(6):1-25.

Wakabayashi, Daisuke and Cecilia Kang. 2018. “Google’s Pichai Faces Privacy and Bias Questions in Congress.” New York Times, December 11.

Wihbey, John, Kenneth Joseph and David Lazer. 2019. “The Social Silos of Journalism? Twitter, News Media and Partisan Segregation.” New Media \& Society 21(4):815-835. 


\section{News Sharing on Social Media}

\section{Mapping the Ideology of}

News Media Content, Citizens, and Politicians

\section{Online Appendix}

\section{Contents}

A Validating estimates for ordinary users

B Estimates with \& without party-level priors

C Ideological diversity in the sharing of national news media

D List of national news media organizations

E Survey questions from social-media-linked survey data 


\section{A Validating estimates for ordinary users}

To validate our link-sharing measure of ideology for ordinary users, we use a unique set of survey and social media data from a representative sample of Twitter users that were collected during the 2016 US presidential election campaign. The survey data were collected through the public opinion firm YouGov and consist of responses to a standard battery of political questions and the Twitter user names of respondents who gave permission for their survey responses be linked to their Twitter timelines. ${ }^{1}$ These data are useful because they allow us to compare common attitudinal and partisan-based measures of ideology with our link-sharing measure as estimated from the news shared by respondents on social media. The survey and Twitter data were collected in 2016 and contain responses and social media posts from 1,341 respondents. However, many social media users are not, in general, politically engaged in their online behavior, and thus we use the subset of data from the 481 respondents (36\%) who posted at least five links to national news media stories. ${ }^{2}$

To estimate the link-sharing ideology of survey respondents, we use data both from these respondents and from politicians (members of Congress, governors, members of executive) when fitting the model. Although the data collection periods for the YouGov respondents (2016) and politicians (2018) differ, we include data from the latter to increase estimation precision (given the relatively small set of survey respondents). Nevertheless, despite temporal differences in collection periods, as we will see, estimates of the news-sharing ideology of ordinary users are highly correlated with survey-based measures from those same users. In the section "Legislators, Citizens, and the Ideological Polarization of News Sharing" of the main article, we make comparisons between ordinary users and politicians from equivalent data-collection periods (albeit without complementary survey data).

We investigate the convergent validity of the social media link-sharing measure by examin-

\footnotetext{
${ }^{1}$ The collection of these survey and social media data was approved by the New York University Institutional Review Board (IRB-12-9058).

${ }^{2}$ Sixty percent of respondents (808) posted at least one national news URL.
} 
Figure A1: Comparison between the link-sharing and survey-based measures of political ideology
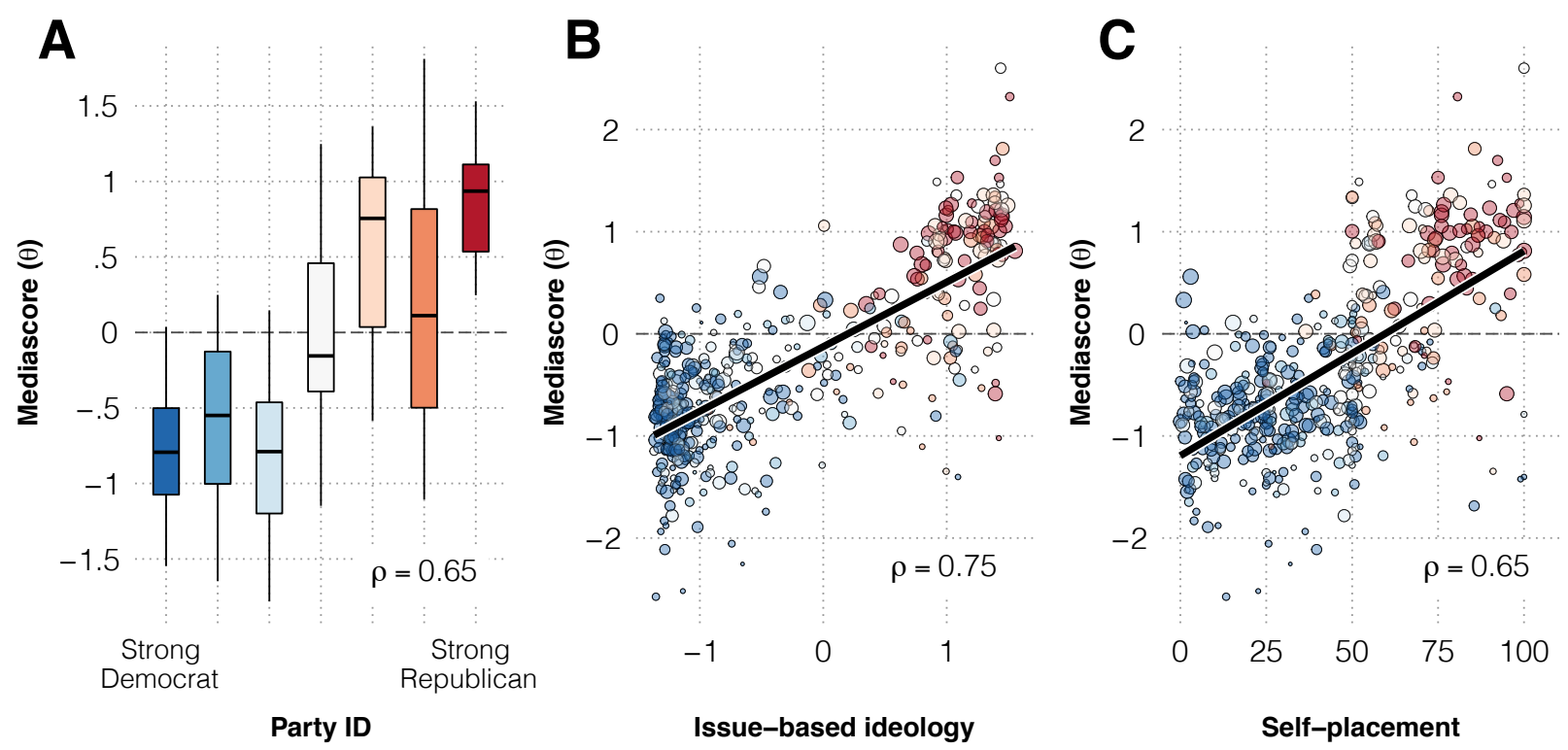

The three panels present the relationship between the social media link-sharing measure of ideology and the three survey-based measures.

ing its relationship with three separate survey-based measures of ideology and partisanship. First, we construct an issue-based ideological scale using survey responses to eight policyrelated questions concerning issues salient during the 2016 US presidential campaign. These questions concern, for example, attitudes toward building a wall on the border with Mexico, expanding the Affordable Care Act, and whether free trade is beneficial to the economy. From responses to the eight policy-related questions, we build a policy-based ideological index $(\alpha=0.83)$ (complete survey question text is available in Appendix E). Second, we use a measure of respondents' judgments about their own ideology by using a standard ideological placement scale. Finally, we measure partisanship using a seven-item scale that ranges from "Strong Democrat" to "Strong Republican.”

We calibrate our expectations about the relationship between the link-sharing and survey measures of ideology by first calculating the correlation between each pair of survey-based measures. As one would expect, pairwise comparisons of measures based on survey data are 
relatively highly correlated, with an average correlation of $0.70 .{ }^{3}$ To examine the relationship between the link-sharing measure and each of the survey-based measures, we present these data graphically in Figure A1. In Panel A, we show that the strength of partisanship is highly correlated with the link-sharing measure of ideology, with independents (center box plot) finding themselves as centrists on the social media measure. In Panels B and C, we see that both the issue-based and self-placement ideological scales are similarly highly correlated with the link-based measure. Finally, as the correlations shown in each panel suggest, ideology as measured by news-sharing behavior is nearly equivalently correlated with each survey-based measure (on average, 0.68 ) as the survey-based measures are correlated between themselves.

\section{B Estimates with \& without party-level priors}

In the main article, we provide estimates of the news-sharing ideology of politicians using a model that includes political party-level information through a hierarchical prior on politicians' ideology scores. In other words, we set priors such that the ideology estimates for Democratic politicians, $\theta_{i, p=\mathrm{D}}$, are given a common prior specific to Democrats:

$$
\theta_{i, p=\mathrm{D}} \sim \operatorname{Normal}\left(\mu_{p=\mathrm{D}}^{(\theta)}, \sigma_{p=\mathrm{D}}^{(\theta)}\right)
$$

and a prior for Republican politicians, $\theta_{i, p=\mathrm{R}}$, a different common prior:

$$
\theta_{i, p=\mathrm{R}} \sim \operatorname{Normal}\left(\mu_{p=\mathrm{R}}^{(\theta)}, \sigma_{p=\mathrm{R}}^{(\theta)}\right)
$$

It is useful for estimation to include such information, especially when data are scarce, such as for politicians who share relatively little news. Nevertheless, it is useful to examine how well the model performs absent this party-level information by fitting a model that includes a prior on the ideology estimates, $\theta_{i p}$ that is common to all actors. We thus fit the same model as in

\footnotetext{
${ }^{3} \rho^{\text {(self-placement, party ID) }}=0.65, \rho^{\text {(self-placement, issues) }}=0.68, \rho^{\text {(issues, party ID) }}=0.77$.
} 
Figure A2: Histograms of the Ideology of Members of Congress Comparing a Model with a Party-level Prior to one with a Common Prior)

\section{Democrat Republican}

Senate

House

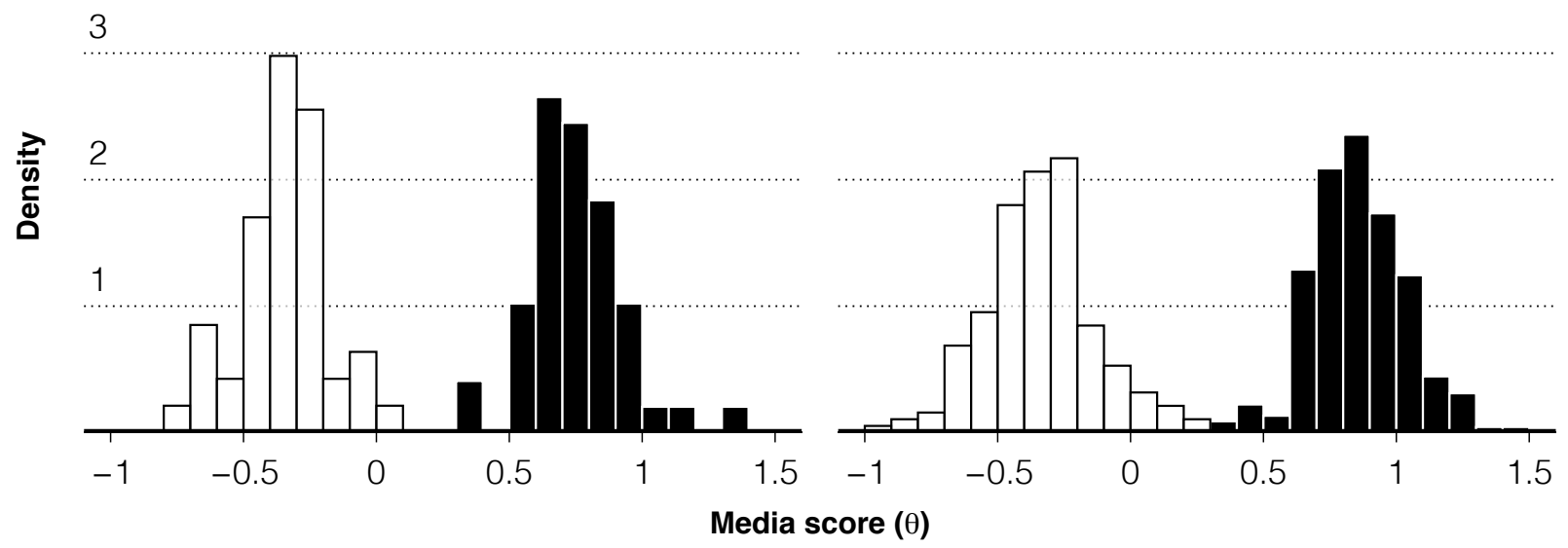

(a) Ideology estimates from a model with party-level priors over members of Congress' ideology parameters $\theta_{i p}$

\section{Democrat $\boldsymbol{\square}$ Republican}

\section{Senate}

House

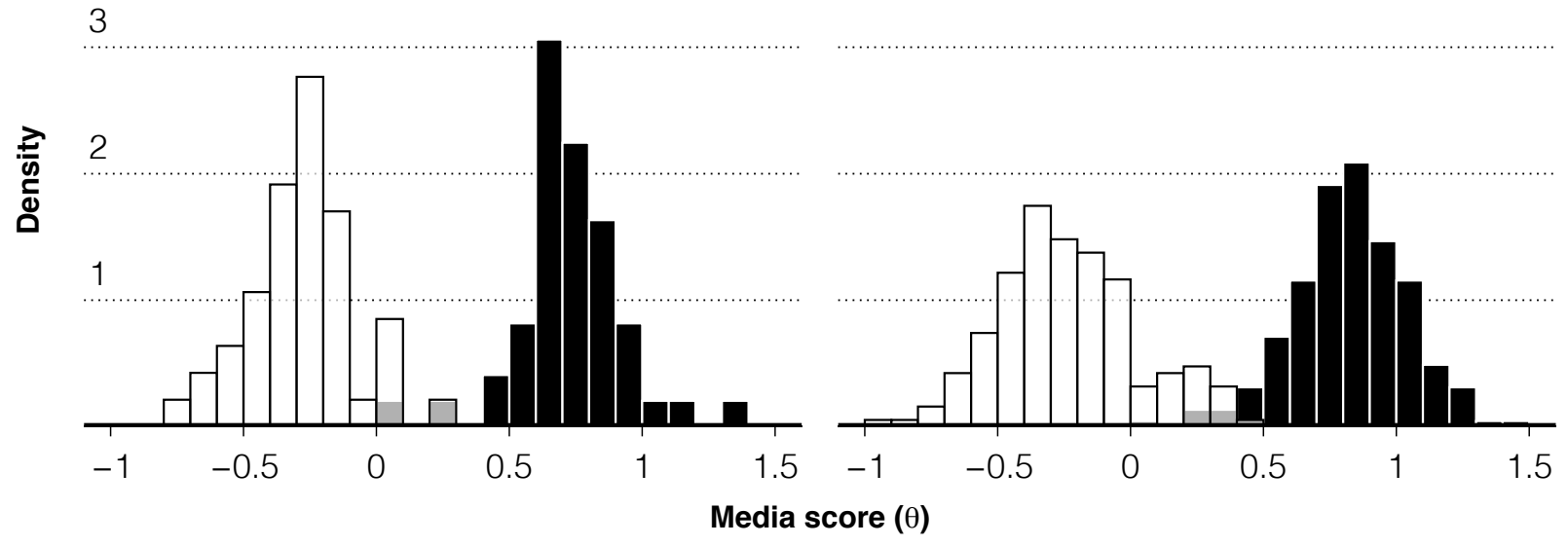

(b) Ideology estimates from a model with a common prior over members of Congress' ideology parameters $\theta_{i}$

This figure presents histograms of the ideology of Members of Congress as estimated from their social media news sharing behavior for a model with separate priors on the ideology parameters for Democratic and Republican politicians (top panel), and without party-level priors (bottom panel). 
Figure A3: Scatterplot comparing Mediascore estimates for members of Congress from a model with party-level priors to one with a common prior)

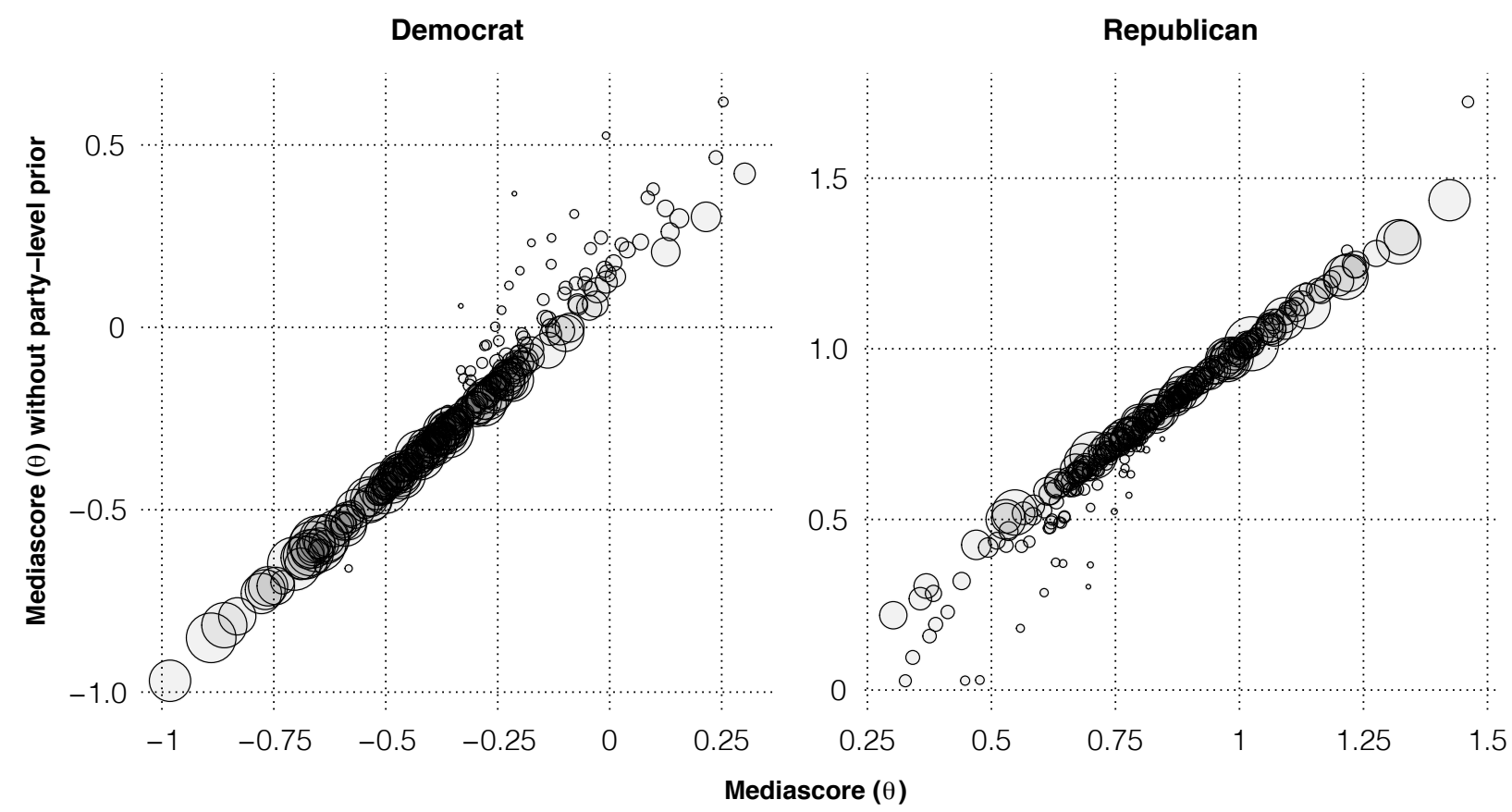

This figure presents differences in estimates of $\theta_{i}$ in a model with a common prior over all parameters $\theta_{i}$ (y axis), and a model with separate priors on $\theta_{i p}$ depending on whether a given politician is a Republican or Democrat ( $\mathrm{x}$ axis). Point size is proportional to the number of national news media URLs shared by each politician.

the main article, but remove any party information by dropping the subscript $p$ on $\theta_{i p}$, thus setting all parameters $\theta_{i}$ to come from a common distribution:

$$
\theta_{i} \sim \operatorname{Normal}\left(\mu^{(\theta)}, \sigma^{(\theta)}\right)
$$

0.98 correlation between the estimates with and without the party-level prior. 0.97 for the within-Democrat estimate, and 0.98 for the within-Republican estimate. The differences in the estimates are driven primarily by Mediascore estimates from members of Congress who tweet very little and therefore are pulled in more strongly by the party-level prior. Thus why the much smaller points in Figure A3 and those that diverge most from the model with party-level priors on $\theta_{i p}$. 


\section{Ideological diversity in the sharing of national news media}

The primary goal of the proposed model is to estimate the ideology of politicians, users, and news media organizations. The variance parameter, $\omega_{m}$, however, also provides a substantively interesting quantity in that it indicates the extent to which political ideology drives sharing of a given domain: a larger value of $\omega_{m}$ indicates that the ideological distance between a user and news media site is less predictive of whether news media domain $m$ is shared by users in generally. For example, we might expect that larger, more general mainstream news organizations (e.g. nytimes.com, washingtonpost.com, wsj.com, foxnews.com) will be shared by users across the political spectrum in comparison to much more niche ideologically narrow news sites. To investigate this, we present in Figure A4 the estimates of $\omega_{m}$ for the 150 most frequently shared news organizations.

[Should add some general comments on the distribution, which makes a lot of sense.]

\section{List of national news media organizations}

Table A1: List of national news domains

\begin{tabular}{rll}
\hline & News Media & Domain \\
\hline 1 & ABC News & abcnews.go.com \\
2 & Accuracy in Media & aim.org \\
3 & AlterNet & alternet.org \\
4 & American Conservative & theamericanconservative.com \\
5 & American Prospect & prospect.org \\
6 & American Spectator & spectator.org \\
7 & American Thinker & americanthinker.com \\
8 & Anti-Media & theantimedia.org \\
9 & Associated Press & apnews.com \\
10 & Atlanta Black Star & atlantablackstar.com \\
11 & attn: & attn.com \\
12 & Axios & axios.com \\
13 & Bipartisan Report & bipartisanreport.com
\end{tabular}


14 BIZPAC Review

15 Black America Web

16 Black News

17 Blavity

18 Bloomberg

19 Boston Review

20 Breitbart

21 Business Insider

22 Buzzfeed News

23 Buzzfeed Politics

24 C-Span

25 Campus Reform

26 CBS News

27 Christian Broadcasting Network

28 Christian Science Monitor

29 Circa

30 City Journal

31 CNBC

$32 \mathrm{CNN}$

33 Color Lines

34 Columbia Journalism Review

35 Commentary

36 Common Dreams

37 Conservative Review

38 Conservative Tribune

39 Cook Political Report

40 Counter Punch

41 CQ Roll Call

42 Crisis Magazine

43 Crooked Media

44 Crooks and Liars

45 CRTV

46 Current Affairs

47 Daily Kos

48 Daily Signal

49 Daily Wire

50 Democracy NOW!

51 Dissent Magazine

52 Drudge Report

53 Elite Daily

54 Epoch Times

55 FactCheck.org

56 FAIR

57 First Things

58 FiveThirtyEight

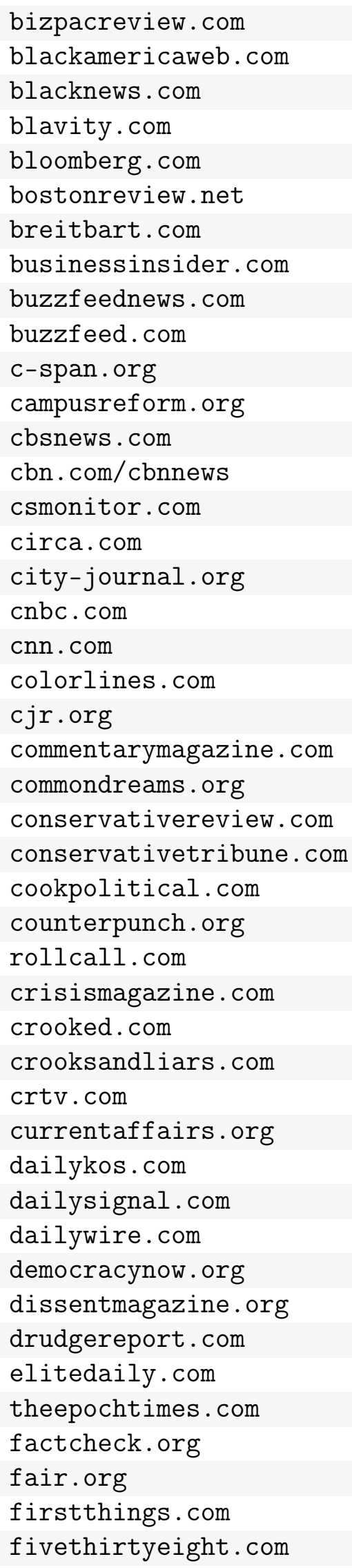


59 Forbes

60 Foreign Affairs

61 Foreign Policy

62 Fortune

63 Fox News

64 Fox News Business

65 Frontpage Mag

66 Full Measure News

67 Gallup News

68 GOOD

69 Governing

70 Ground Truth

71 Harper's Magazine

72 Harvard Business Review

73 HLN

74 HotAir

75 Huffington Post

76 In These Times

77 Independent Journal Review

78 Infowars

79 Inquisitr

80 InstaPundit

81 Intellihub News

82 International Business Times

83 Jacobin

84 Jezebel

85 Just Security

86 Lawfare

87 Levin TV

88 LifeZette

89 Mad World News

90 Mashable Social Good

91 McClatchy

92 Media Matters

93 Media Research Center

94 Media Research Center CNS News

95 Media Research Center MRCTV

96 Media Research Center Newsbusters

97 Mediaite

98 Mic News

99 Mint Press News

100 Morning Consult

101 Mother Jones

102 Ms. Magazine

103 MSNBC

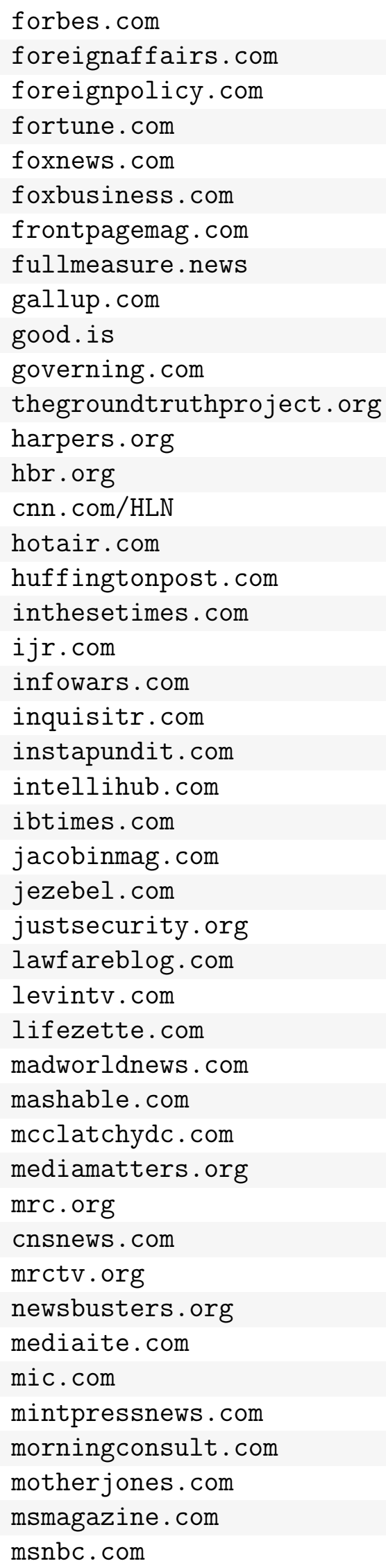


104 National Affairs

105 National Interest

106 National Journal

107 National Review

108 NBC News

109 New York Magazine

110 New York Observer

111 Newsmax

112 NewsOne

113 Newsweek

114 Nieman Journalism Lab

115 Now This

116 NPR

117 One American News

118 OZY

119 Pacific Standard

120 Palmer Report

121 PBS

122 PEW Research

123 PJ Media

124 Political Insider

125 Politico

126 Politicus USA

127 Politifact

128 Poynter

129 Project Veritas

130 Project Veritas Action

131 ProPublica

132 Public Policy Polling

133 Quartz

134 Quinnipiac Polling

135 Rare

136 Rasmussen Reports

137 Raw Story

138 Real Clear Politics

139 Reason

140 Red State

141 Reuters

142 Reuters TV

143 Reveal

144 Reverb Press

145 Right Side Broadcasting Network

146 Right Wing News

147 Right Wing Watch

148 Russia Today

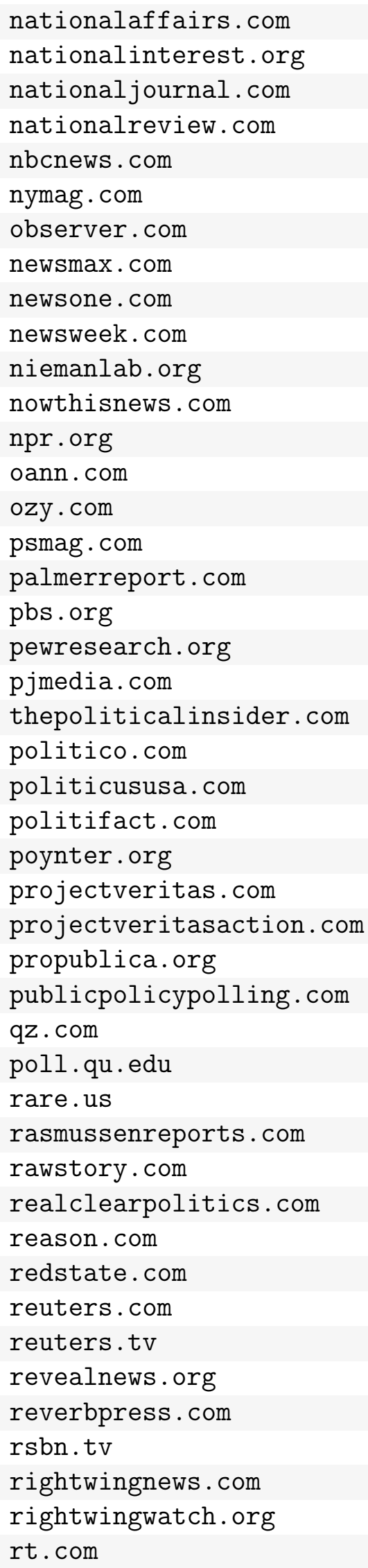


149 Salon

150 Share Blue

151 Slate

152 Snopes

153 Southern Poverty Law Center

154 Splinter

155 Sputnik

156 Stars and Stripes

157 Talking Points Memo

158 Task and Purpose

159 Telemundo Noticias

160 The Atlantic

161 The Baffler

162 The Blaze

163 The Bulwark

164 The Center for Investigative Reporting

165 The Center for Public Integrity

166 The Conservation US

167 The Daily Banter

168 The Daily Beast

169 The Daily Caller

170 The Daily Dot

171 The Daily Signal

172 The Economist US

173 The Federalist

174 The Guardian US

175 The Hill

176 The Intercept

177 The Marshall Project

178 The McLaughlin Group

179 The Nation

180 The New Republic

181 The New York Post

182 The New York Times

183 The New Yorker

184 The Onion

185 The Politichicks

186 The Progressive

187 The Real News

188 The Resurgent

189 The Right Scoop

190 The Root

191 The Stream

192 The Voice of America

193 The Week

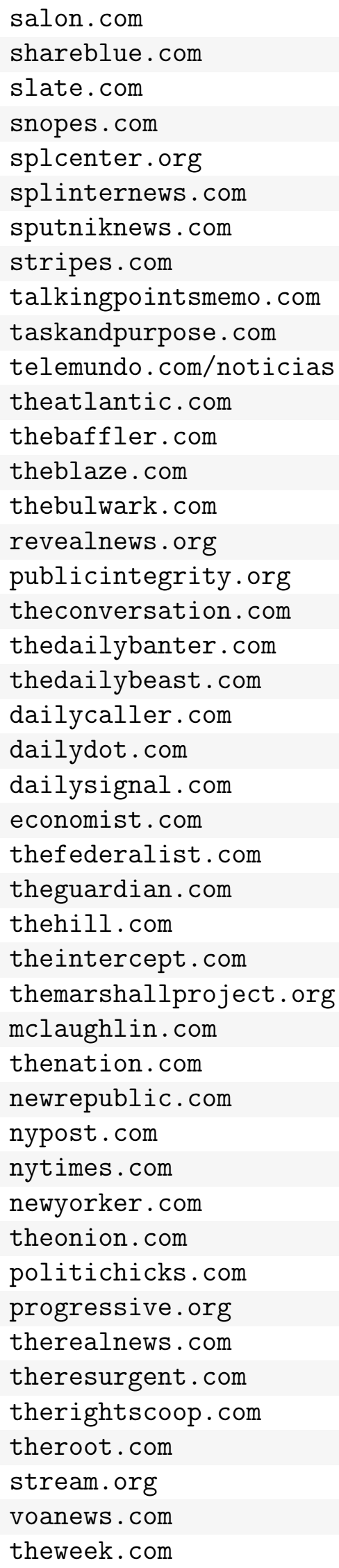


194 The Weekly Standard

195 The Young Turks

196 Think Progress

197 TIME

198 Townhall

199 Truth Dig

200 Truthout

201 Twitchy Team

202 United Press International

203 Univision Noticias

204 US News \& World Report

205 USA Today

206 Vanity Fair

207 VICE

208 Vox

209 Wall Street Journal

210 Washington Examiner

211 Washington Free Beacon

212 Washington Monthly

213 Washington Post

214 Washington Times

215 Western Journal

216 World Affairs

217 World News Network

218 World Politics Review

219 World Socialist Web Site

220 Yahoo News weeklystandard.com

tytnetwork.com

thinkprogress.org

time.com

townhall.com

truthdig.com

truth-out.org

twitchy.com

upi.com

univision.com

usnews.com

usatoday.com

vanityfair.com

vice.com

vox.com

ws j. com

washingtonexaminer.com

freebeacon.com

washingtonmonthly.com

washingtonpost.com

washingtontimes. com

westernjournal.com

worldaffairsjournal.org

wn. com

worldpoliticsreview.com

wsws.org

yahoo.com/news

\section{E Survey questions from social-media-linked survey data}

Below we present the question wording and response categories for the questions used to examine the relationship between the news-sharing measure of political ideology and the survey-based measures.

\section{Issue-based ideological scale}

To build the issue-based ideological scale, the survey indicators used were constructed from responses to the following 8 questions. 


\section{Figure A4: Variance parameters $\omega_{m}$ for the 150 most shared news domains}

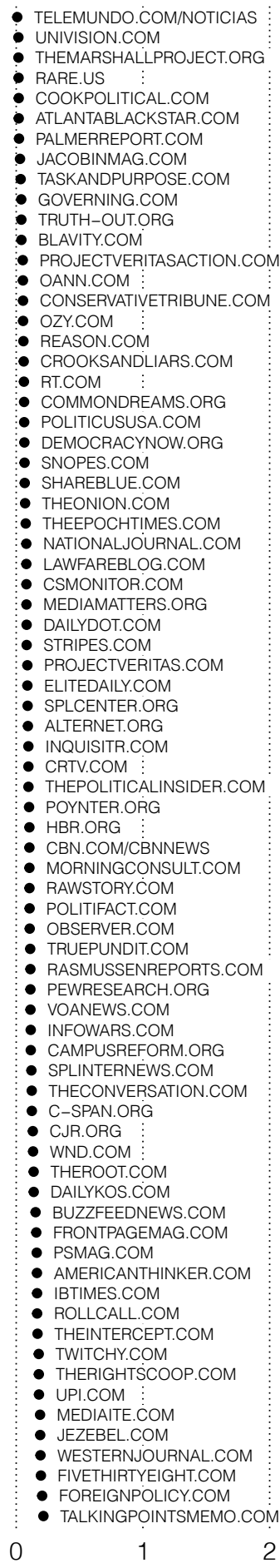

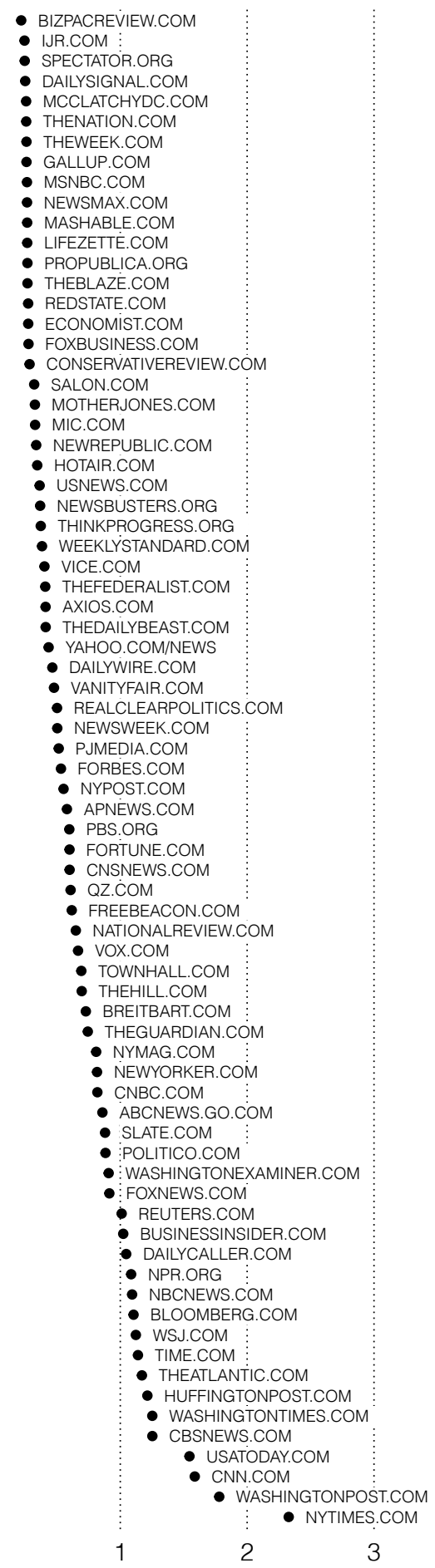

$\omega_{\mathrm{m}}$ (variance parameter)

This graph shows the parameters $\omega_{m}$ for the 150 most frequently shared news media domains. 


\section{Immigration}

As shown on the scale below, some people think that the U.S. should deport all illegal immigrants and others think we should instead provide them with a path to citizenship. And of course others have opinions in between, such as allowing illegal immigrants to obtain guest worker status.

Please place yourself on this scale. Then place each of the following national figures on the same scale. $[0,1, \ldots, 99,100]$

0: Deport all illegal immigrants back to their home countries 100: Provide all illegal immigrants an eventual path to citizenship

\section{Building a wall}

As shown on the scale below, some people think we should build a wall between the United States and Mexico, while others think that this would be a foolish waste of resources and not address real issues of immigration. And of course some people have opinions in between.

Please place yourself on this scale. Then place each of the following national figures on the same scale. $[0,1, \ldots, 99,100]$

0: Build a wall

100: Address immigration Issues via other means

\section{Tariffs}

As shown on the scale below, some people think that we should increase tariffs on goods from China to protect American jobs from unfair 
competition, others think that this would lead to a trade war that would harm the American economy and cost jobs. And of course some people have opinions in between.

Please place yourself on this scale. Then place each of the following national figures on the same scale. $[0,1, \ldots, 99,100]$

0: Increase tariffs on China

100: A trade war would cost jobs

\section{Free trade}

As shown on the scale below, some people think that we should reduce trade with other countries to protect American jobs from foreign competition, while others believe that we should increase trade to benefit American consumers and create more markets for American goods. And of course others have opinions in between.

Please place yourself on this scale. Then place each of the following national figures on the same scale. $[0,1, \ldots, 99,100]$

0: Reduce free trade with other countries

100: Increase free trade with other countries

\section{Use of military force}

As shown on the scale below, some people think that military force should be used only as a last resort, while other people think that military force is usually the best way to solve international problems And of course, some 
other people have opinions somewhere in between.

Please place yourself on this scale. Then place each of the following national figures on the same scale. $[0,1, \ldots, 99,100]$

0: Military force should be used only as a last resort 100: Military force is usually the best way to solve international problems

\section{Health care}

The Affordable Care Act, signed into law by President Obama in 2010, restructured the U.S. health care system. As shown on the scale below, some people think that the health care law should be repealed entirely, while others think it should be expanded to cover more people and services. And of course, some other people have opinions somewhere in between, such as simply keeping the law as it is now.

Please place yourself on this scale. Then place each of the following national figures on the same scale. $[0,1, \ldots, 99,100]$

0: Completely repeal the entire health care law

100: Expand the health care law's coverage

\section{Barring Muslims from entering the US}

As shown on the scale below, some people think we should bar Muslims from entering the US to prevent terrorism, others think it is an essential aspect of the United States that we do not discriminate based on religion, and of course some people have opinions in between. 
Please place yourself on this scale. Then place each of the following national figures on the same scale. $[0,1, \ldots, 99,100]$

0: Bar Muslims From Entering the US

100: Do Not Discriminate Based on Religion

\section{Obamacare}

As shown on the scale below, some people think we should repeal Obamacare and start over to handle health insurance, others think we should leave Obamacare in place, but expand coverage, and of course some people have opinions in between.

Please place yourself on this scale. Then place each of the following national figures on the same scale. $[0,1, \ldots, 99,100]$

0: Repeal Obamacare, Start Over

100: Keep Obamacare, Expand Coverage

\section{Ideological self-placement}

The ideological self-placement measure was collected from the following question:

As shown on the scale below, some people in the U.S. tend to identify more with the political left, while others tend to identify more with the political right. And of course, some other people have opinions somewhere in between. Please place yourself on this scale. Then place both of the U.S.'s two major parties on the same scale. Then, place each of the 
following candidates for president on the same scale. $[0,1, \ldots, 99,100]$

0: Far left

100: Far right

\section{Party Identification}

The party identification measure was collected from the following two-part (conditional) question:

Generally speaking, do you think of yourself as a...

Democrat

Republican

Independent

Other

Not sure

The above question was followed by options to probe the strength of each respondent's partisanship:

Strong Democrat (if response was Democrat)

Not very strong Democrat (if response was Democrat)

Strong Republican (if response was Republican)

Not very strong Republican (if response was Republican)

The Democratic Party (if response was Independent or Other)

The Republican Party (if response was Independent or Other)

Neither (if response was Independent or Other) 
Not sure (if response was Independent or Other)

\section{References}

